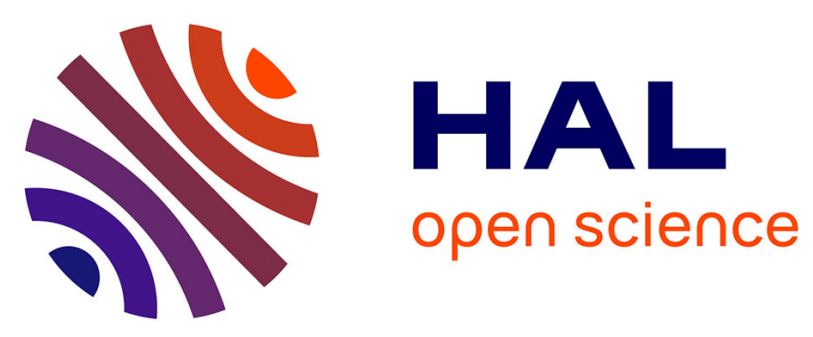

\title{
Assessing the effect of a Saharan dust storm on oxygenated organic compounds at Izaña, Tenerife (July-August 2002)
}

G. Salisbury, J. Williams, V. Gros, S. Bartenbach, X. Xu, H. Fischer, R. Kormann, M. de Reus, M. Zöllner

\section{To cite this version:}

G. Salisbury, J. Williams, V. Gros, S. Bartenbach, X. Xu, et al.. Assessing the effect of a Saharan dust storm on oxygenated organic compounds at Izaña, Tenerife (July-August 2002). Journal of Geophysical Research: Atmospheres, 2006, 111 (D22), pp.D22303. 10.1029/2005JD006840 . hal03117214

\section{HAL Id: hal-03117214 \\ https://hal.science/hal-03117214}

Submitted on 13 Apr 2021

HAL is a multi-disciplinary open access archive for the deposit and dissemination of scientific research documents, whether they are published or not. The documents may come from teaching and research institutions in France or abroad, or from public or private research centers.
L'archive ouverte pluridisciplinaire HAL, est destinée au dépôt et à la diffusion de documents scientifiques de niveau recherche, publiés ou non, émanant des établissements d'enseignement et de recherche français ou étrangers, des laboratoires publics ou privés. 


\title{
Assessing the effect of a Saharan dust storm on oxygenated organic compounds at Izaña, Tenerife (July-August 2002)
}

\author{
G. Salisbury, ${ }^{1}$ J. Williams, ${ }^{1}$ V. Gros,${ }^{1}$ S. Bartenbach, ${ }^{1}$ X. Xu, ${ }^{1}$ H. Fischer, ${ }^{1}$ R. Kormann, ${ }^{1}$ \\ M. de Reus, ${ }^{1}$ and M. Zöllner ${ }^{1}$ \\ Received 1 November 2005; revised 4 April 2006; accepted 28 June 2006; published 18 November 2006.
}

[1] In July-August 2002 the field measurement campaign Mineral Dust and Tropospheric Chemistry (MINATROC) was carried out at the Global Atmosphere Watch station at Izaña, Tenerife, to study the interaction of mineral dust aerosol and tropospheric chemistry. Organic trace gas mixing ratios were determined for the following: alkanes (e.g., propane); alkenes (isoprene); aromatic compounds (toluene); and oxygenated species (CO, methanol, formaldehyde, acetaldehyde, and acetone) simultaneously with aerosol measurements of dust. Local emissions of biogenic (isoprene and methanol) and anthropogenic compounds (CO and toluene) were observed at Izaña by day. Nighttime mixing ratios of organic species were interpreted as representative of the Atlantic free troposphere. A local production and loss budget for formaldehyde suggested that isoprene dominates production by day, and a significant dry deposition velocity is estimated at night of $0.74 \mathrm{~cm} / \mathrm{s}$. The total reactivity of the organic trace gases measured to $\mathrm{OH}$ is estimated as $1.7 \mathrm{~s}^{-1}$ by day and $0.7 \mathrm{~s}^{-1}$ by night. During the campaign a dense Saharan dust plume, with aerosol masses exceeding $500 \mu \mathrm{g} \mathrm{m}^{-3}$, persisted for 3 days. Air masses containing dust appeared to be generally more polluted (in acetone and $\mathrm{CO}$ ) than the prevailing westerly flow, but local biogenic emissions were little affected (e.g., methanol and isoprene). Although during the dust period the daily cycles and the absolute concentrations of some oxygenated species are different (e.g., acetaldehyde), these changes could not be attributed unequivocally to heterogeneous reactions on dust.

Citation: Salisbury, G., J. Williams, V. Gros, S. Bartenbach, X. Xu, H. Fischer, R. Kormann, M. de Reus, and M. Zöllner (2006), Assessing the effect of a Saharan dust storm on oxygenated organic compounds at Izaña, Tenerife (July-August 2002), J. Geophys. Res., 111, D22303, doi:10.1029/2005JD006840.

\section{Introduction}

[2] Each year an estimated $240 \pm 80 \mathrm{Tg}$ of Saharan dust is transported annually from Africa at $20^{\circ} \mathrm{S}$ to $30^{\circ} \mathrm{N}$ predominately over the Atlantic Ocean [Kaufman et al., 2005]. These dust outbreaks continue through the year and have been well documented by satellite images. Dust-laden air represents an interface region between the atmosphere and the pedosphere, where tropospheric chemistry may be affected by heterogeneous reaction or attenuated photolysis rates. The interaction between dust aerosol and photochemistry has been the focus of field measurement and modeling research in recent years [e.g., Dentener et al., 1996; Putaud et al., 1999; Maring et al., 2000; Martin et al., 2003]. Special emphasis has been given to reactions on mineral dust aerosol, since these particles provide a large surface area for heterogeneous reactions in the troposphere [Usher et al., 2003].

[3] Several previous field campaigns have reported a correlation between high dust loadings and low gas phase

\footnotetext{
${ }^{1}$ Department of Atmospheric Chemistry, Max-Planck-Institut für Chemie, Mainz, Germany.

Copyright 2006 by the American Geophysical Union. 0148-0227/06/2005JD006840
}

mixing ratios of $\mathrm{O}_{3}$ and $\mathrm{HNO}_{3}$ [e.g., de Reus et al., 2000; Hanke et al., 2003]. Moreover it is has been established that dust-poor air masses originating from North Africa had significantly higher $\mathrm{O}_{3}$ concentrations than those which carried dust [Bonasoni et al., 2004]. Several chemical modeling studies have also investigated the potential mitigating effect of dust on ozone, nitrogen species, and $\mathrm{HO}_{\mathrm{x}}$ $\left(\mathrm{OH}\right.$ and $\left.\mathrm{HO}_{2}\right)$ [e.g., Zhang et al., 1994; Zhang and Carmichael, 1999]. Bian and Zender [2003] investigated the effect of reduced photolysis rates and heterogeneous chemistry on the tropospheric trace gas mixing ratios. They concluded that both processes cause a combined decrease in global mean $\mathrm{O}_{3}$ of $0.7 \%$, and $11.1 \%$ for $\mathrm{OH}, 5.2 \%$ for $\mathrm{HO}_{2}$ and $3.5 \%$ for $\mathrm{HNO}_{3}$. The effects of heterogeneous removal reactions clearly dominated over the reduced photolysis rates.

[4] Since it has been established that dust storms can induce tangible effects in the atmospheric chemistry of ozone, we may expect an impact on the chemistry and hence global budgets of certain organic trace species. Most susceptible would be the oxygenated compounds (e.g., methanol, acetone, formaldehyde and acetaldehyde) whose atmospheric formation and destruction are linked to photolysis processes, and because of their polarity, more likely to be involved in heterogeneous reactions. If dust has a strong 


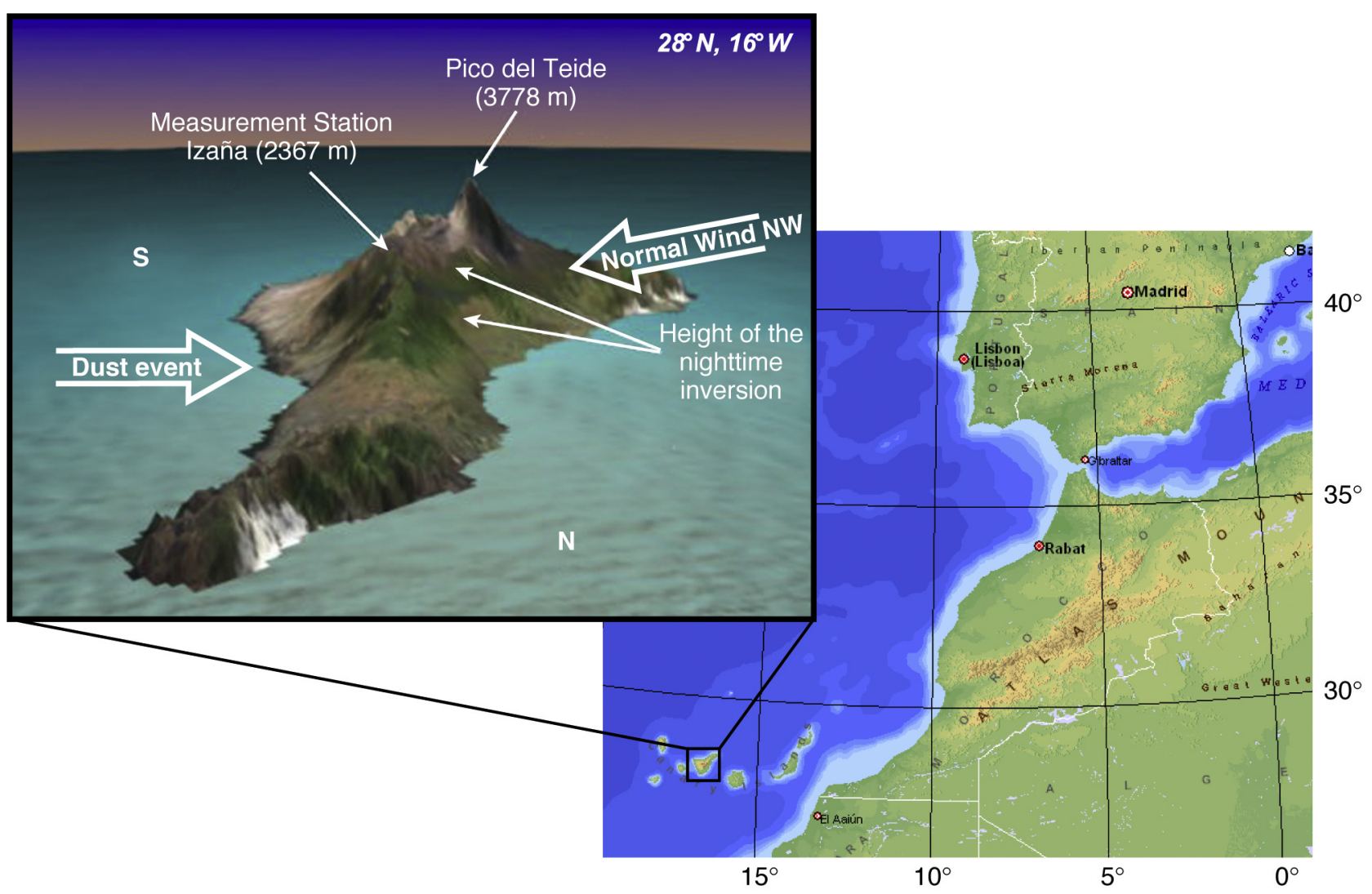

Figure 1. Map of Tenerife showing site of Izaña measurement station.

effect on the atmospheric chemistry of oxygenated species then pronounced changes in ambient mixing ratios can be expected when dust storms are encountered. Oxygenated organic species play many important roles in the atmosphere [Williams, 2004, and references therein]. In the upper troposphere or over the remote ocean, organic species such as carbonyls may act as important radical sources [McKeen et al., 1997; Jaegle et al., 2001] and can thereby influence the global ozone budget. Measurements made over the Pacific Ocean have shown that significant mixing ratios of many oxidized organic species can be found even in remote regions [Singh et al., 2001, 2003]. However, the direct sources, chemical precursors and sinks of many major oxygenated organic species are not yet well established, and various global budgets have been proposed [Singh et al., 2001; Jacob et al., 2002; Galbally and Kirstine, 2002; Heikes et al., 2002].

[5] In this study we investigate the effect of mineral dust on the oxygenated organic species through field measurements. We examine the volume mixing ratios and daily cycles of the measured organic compounds under normal conditions at Izaña, Tenerife, and then contrast these with those in a large dust storm. The contribution of these compounds to the atmospheric reactivity is assessed under both conditions.

\section{Mineral Dust and Tropospheric Chemistry (MINATROC) Experiment and Local Meteorology}

[6] In this paper we will present observations of a field experiment Mineral Dust and Tropospheric Chemistry
(MINATROC), performed in July-August 2002 at the Izaña observatory on the island of Tenerife, Spain. The Izaña observatory is part of the World Meteorological Organization (WMO) Global Atmosphere Watch (GAW) network, and is operated by the Spanish Meteorological Institute. The station is situated on a mountain ridge on the island of Tenerife at $2360 \mathrm{~m}$ above sea level (asl, $28^{\circ} 18^{\prime} \mathrm{N}$, $16^{\circ} 29^{\prime} \mathrm{W}$ ); see Figure 1 . The sides of the island are forested up to approximately $1.5 \mathrm{~km}$. The synoptic situation over the Canary Islands is usually dominated by a subtropical anticyclone, centered over the Azores [Carslaw et al., 1997]. Deviations in the position of this anticyclone generally determine the origin of the air masses observed at the Izaña observatory. Intensive aerosol and trace gas measurements were performed between 15 July and 15 August 2002. The influence of mineral dust on the chemistry of the troposphere could be studied extensively during this period, since, besides several smaller dust episodes, a major dust event influenced the site between 28 and 31 July 2002. The prevailing wind during the measurement period was northwest; however, during the dust event the wind was from the southeast. Aerosol index images from the TOMS satellite indicate that this dust plume originated in western Algeria and its border region with Mali and Mauritania. Back trajectory calculations suggest that the air masses were lifted from between 500 and $1500 \mathrm{~m}$ above ground level to the measurement altitude of about $2.5 \mathrm{~km}, 2.5-3$ days before arrival at the Izaña measurement station. Lidar measurements indicate that the Saharan dust plume extended 
Table 1. Instrumentation Used for Trace Gas Measurements During MINATROC Including Measurement Uncertainty and Detection Limit

\begin{tabular}{|c|c|c|c|c|}
\hline Species & Measurement Principle & Instrument & Uncertainty & Detection Limit \\
\hline $\mathrm{O}_{3}$ & UV absorption & Ansyco 41M & $<5 \%$ & $1 \mathrm{ppbv}$ \\
\hline $\mathrm{CO}$ & gas chromatograph & Thermo-Electron & $5 \%$ & \\
\hline NO & $\begin{array}{l}\text { chemiluminescence } \\
\text { detector (CLD) }\end{array}$ & ECOPHYSICS CLD 790SR & $3 \%$ & 8 pptv \\
\hline $\mathrm{NO}_{2}$ & $\begin{array}{l}\text { CLD and photolytic } \\
\text { converter (PLC) }\end{array}$ & $\begin{array}{l}\text { ECOPHYSICS CLD } \\
790 \text { SR and PLC } 760\end{array}$ & $\begin{array}{l}8 \% \text { at night, } \\
20 \% \text { during the day }\end{array}$ & 24 pptv \\
\hline $\mathrm{HCHO}$ & $\begin{array}{l}\text { fluorescence detector } \\
\text { (Hantzsch reaction) }\end{array}$ & Aero Laser AL4021 & $5 \%$ & 23 pptv \\
\hline $\mathrm{H}_{2} \mathrm{O}_{2}$ & $\begin{array}{l}\text { fluorescence detector } \\
\quad \text { (dual enzyme tecnique) }\end{array}$ & Aero Laser AL2001CA & $20 \%$ & 60 pptv \\
\hline $\mathrm{CH}_{3} \mathrm{OOH}$ & fluorescence detector & AL2001CA & $100 \%^{\mathrm{a}}$ & $60 \mathrm{pptv}$ \\
\hline $\mathrm{RO}_{\mathrm{x}}$ & $\begin{array}{l}\text { chemical amplifier and } \\
\text { photoluminescence detector }\end{array}$ & PERCA and Luminox LMA-3 & $30-40 \%$ & 2 pptv \\
\hline $\begin{array}{l}\text { Acetone, } \\
\text { methanol, isoprene }\end{array}$ & $\begin{array}{l}\text { proton transfer reaction } \\
\text { mass spectrometer (PTR-MS) }\end{array}$ & & $<28 \%$ & $\begin{array}{l}55 \text { pptv, } 213 \text { pptv, } \\
46 \text { pptv, respectively }\end{array}$ \\
\hline Propane, butane & $\begin{array}{c}\text { gas chromatograph-mass } \\
\text { spectrometer (GC-MS) }\end{array}$ & Agilent GC-MS 6890/5973 & $<15 \%$ & 3 pptv \\
\hline terpenes & two-dimensional GC (2D-GC) & Agilent GC-MS 6890 ZOEX jets & $7 \%$ & $0.1-0.5 \mathrm{pptv}$ \\
\hline $\mathrm{JO}^{1} \mathrm{D}$ & filter radiometer & METCON & $20^{\mathrm{b}}-30 \%{ }^{\mathrm{c}}$ & $8 \times 10^{-7} \mathrm{~s}^{-1}$ \\
\hline $\mathrm{JNO}_{2}$ & filter radiometer & METCON & $10^{\mathrm{b}}-20 \%{ }^{\mathrm{c}}$ & $8 \times 10^{-7} \mathrm{~s}^{-1}$ \\
\hline
\end{tabular}

${ }^{a}$ Estimated uncertainty for $\mathrm{CH}_{3} \mathrm{OOH}$ as organic peroxide signal assumed to be entirely $\mathrm{CH}_{3} \mathrm{OOH}$ which has a collection efficiency of $60 \%$.

${ }^{\mathrm{b}}$ For solar zenith angles $<60^{\circ}$.

${ }^{\mathrm{c}}$ For solar zenith angles between 60 and $70^{\circ}$.

to an altitude of about $7 \mathrm{~km}$ (G. P. Gobbi, personal communication, 2003).

\section{Instrumentation}

[7] A suite of instruments to measure atmospheric trace gases was operated by the Max Planck Institute for Chemistry, Mainz, Germany, from two laboratory containers. A complete list of the trace gas instruments that are relevant for this study, together with their associated uncertainties and detection limits, has been given in Table 1. A sample air inlet was placed at the roof of both containers about $4 \mathrm{~m}$ above the ground and a fast flow of approximately $80 \mathrm{~L} / \mathrm{min}$ through the 10-m-long, 1.91-cm-diameter PFA Teflon inlet kept residence times at approximately $20 \mathrm{~s}$. Fractions of this flow were sampled for the instruments measuring organic species (PTR-MS, 2D-GC and flask sampling). The upward looking $\mathrm{JNO}_{2}$ and $\mathrm{JO}^{1} \mathrm{D}$ filter radiometers were deployed directly at roof of the container at about $3 \mathrm{~m}$ above ground level, while the downward looking $\mathrm{JNO}_{2}$ and $\mathrm{JO}^{1} \mathrm{D}$ filter radiometers were mounted at a height of $1.5 \mathrm{~m}$ above ground level.

[8] Measurements of a range of organic species were performed using a proton transfer reaction mass spectrometer (PTR-MS). Ambient air was drawn at approximately $100 \mathrm{ml} / \mathrm{min}$ through an 1/8 inch $(3.18 \mathrm{~mm})$ PFA Teflon line from the main high-flow inlet described above. The entire inlet system of the PTR-MS including switching valves was composed of Teflon. Inside this instrument organic species are chemically ionized by the proton transfer with $\mathrm{H}_{3} \mathrm{O}^{+}$ ions and the products are detected with a quadrupole mass spectrometer [Lindinger et al., 1998]. In this study the measurements of acetone (mass 59), methanol (mass 33), acetaldehyde (mass 45), isoprene (mass 69), methacrolein and methyl vinyl ketone (mass 71), and toluene (mass 93) are reported. The isoprene mixing ratios measured with the PTR-MS, however, should be regarded as upper limits, because of other possible contributions to this mass [Williams et al., 2001]. It should be noted that generally measurements of acetaldehyde are currently viewed with some skepticism because of recently reported potential sampling problems for this species. Apel et al. [2003] reported an artifact for acetaldehyde can occur within inlets, even on inert surfaces. Interferences in stratospherically influenced air have been reported by Northway et al. [2004] and Singh et al. [2004] for PTR-MS and GC systems respectively. The PTR-MS instrument used here has also subsequently recorded anomalous increases in acetaldehyde in the stratosphere where such species are most unlikely to be present. Furthermore, acetaldehyde measurements appear to be inconsistent with simultaneously measured species such as PAN and ethane when compared with models [Singh et al., 2004; Lewis et al., 2005]. Despite this uncertainty, the acetaldehyde data are included in this paper as we are specifically examining the potential effect of surface reactions and if acetaldehyde can be produced on inlet surfaces it may also be generated on aerosols. Nonetheless, the acetaldehyde data presented here must also be interpreted with caution. More details about the measurement technique and calibration procedure are given by Salisbury et al. [2003]. For the measurement of non methane hydrocarbons (NMHC), precursors of the oxygenates examined here, stainless steel canister samples were taken every 3 or 6 hours during the campaign, which were analyzed in the laboratory of the Max Planck Institute in Mainz, using a gas chromatograph-mass spectrometer system (GC-MS). Because of the setup of the GC-MS system only hydrocarbons with more than $2 \mathrm{C}$ atoms were analyzed. More details about the collection of the samples, the GC-MS system and its calibration procedure are given by Gros et al. [2003]. In addition, a GCxGC-FID system was deployed to measure the less volatile VOCs from $\mathrm{C} 7-$ C11. This instrument chromatographically separates the ambient sample in two dimensions: one according to boiling 


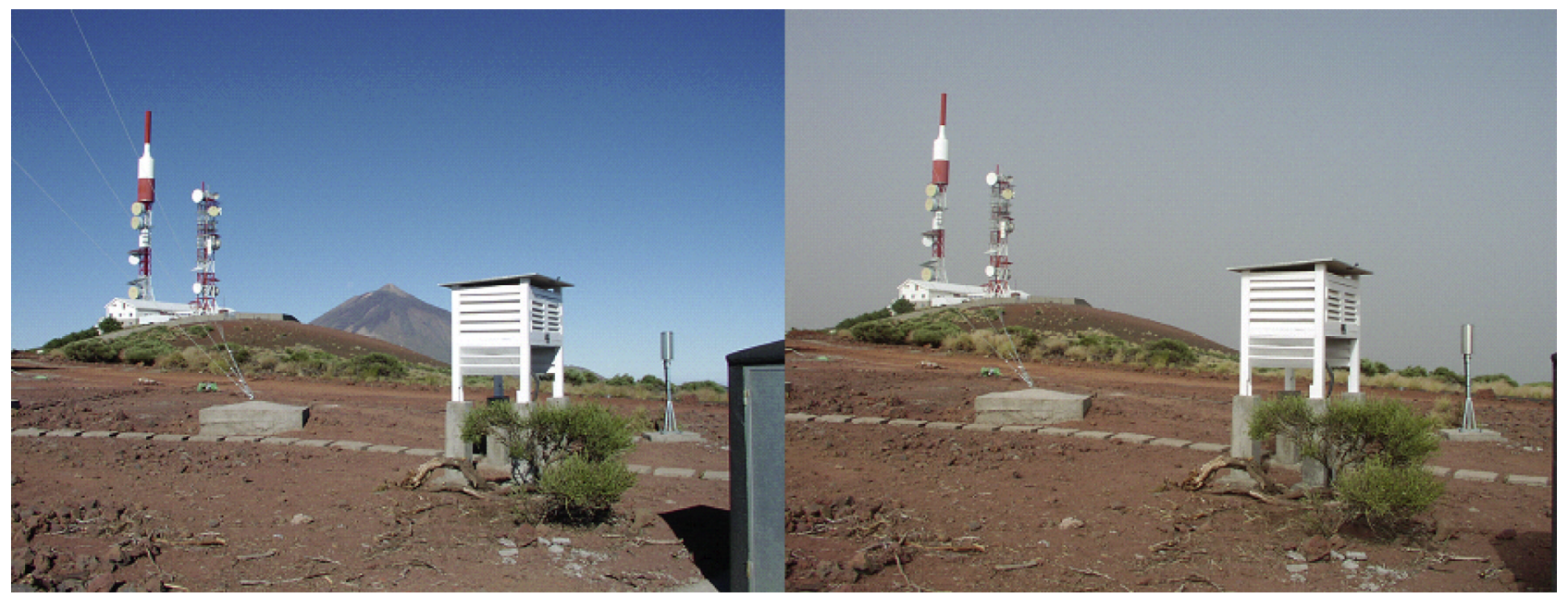

Figure 2a. View of "Pico del Teide" from the measurement site: (left) on a dust free day and (right) during the main dust event (30 July).

point and one according to polarity. It is therefore referred to here as 2D-GC. Complete details of this system are given elsewhere [Xu et al., 2003].

[9] Many instruments used here were also deployed during a field experiment at Mount Cimone in June 2000. Therefore for a detailed description of the $\mathrm{O}_{3}, \mathrm{CO}, \mathrm{RO}_{\mathrm{x}}, \mathrm{NO}$ and $\mathrm{NO}_{\mathrm{y}}$ instruments the reader is referred to Fischer et al. [2003]. For the other instruments more details are given below. In addition to this suite of instrumentation, two wet chemistry techniques were used to determine formaldehyde and hydrogen peroxide. A liquid chemistry fluorescence detector (AERO laser model AL 4021) was used to measure formaldehyde ( $\mathrm{HCHO})$. The instrument first strips the $\mathrm{HCHO}$ from the ambient air into a strongly diluted $\mathrm{H}_{2} \mathrm{SO}_{4}$ solution, after which it reacts with acetylacetone and ammoniumacetate to form 3,5-diacetyl-1,4-dihydrolutidine (DDL) following the Hantzsch reaction. The fluorescence signal of the excited reaction product is detected by a photomultiplier at $510 \mathrm{~nm}$. The same instrument has been employed during a previous aircraft campaign [Kormann et al., 2003]. For the determination of $\mathrm{H}_{2} \mathrm{O}_{2}$ and $\mathrm{CH}_{3} \mathrm{OOH}$ a second liquid chemistry fluorescence detector has been used (AERO laser model AL 2001CA). Full experimental details of this system including gas and liquid phase calibration methods are given by de Reus et al. [2005].

[10] Aerosol measurements were performed from a mobile laboratory by the Joint Research Centre, Ispra, Italy. Dry aerosol size distributions in the size range 6-600 nm diameter were measured with a custom built Vienna type differential mobility analyzer (DMA), using a TSI CPC model 3010 as particle counter (Thermo Systems Inc. condensation particle counter). The number size distribution of coarse particles was determined with an optical particle counter (OPC, GRIMM model 1.108) in 15 size classes from $300 \mathrm{~nm}$ to $10 \mu \mathrm{m}$ diameter. Note that the aerosols entering the OPC have not been dried; however, for the low relative humidities $(<60 \%)$ observed during the campaign, the observed aerosol diameter can be regarded as dry diameter. Combining the data of both instruments provides the aerosol size distribution between $6 \mathrm{~nm}$ and $10 \mu \mathrm{m}$ diameter, from which the total aerosol surface area and volume was calculated.

\section{Results}

\subsection{Overview of the Measurements}

[11] The broad purpose of the MINATROC project was to investigate the effects of airborne dust on atmospheric chemistry. During the intensive field campaign in Tenerife in 2002 several dust events were observed, one of which was much more intense (5-7 times, based on the optical particle counter measurements) than the others. During this large dust event (28-31 July), visibility at Izaña was severely reduced, and the normally very prominent landmark of Mount Teide, only approximately $13 \mathrm{~km}$ from the measurement station, disappeared from view entirely; see Figure 2a. Figure $2 \mathrm{~b}$ shows the total aerosol volume measured at Izaña using an optical particle counter for the period 28 July to 14 August 2002; these data were used to define the limits of both the large dust event and the three smaller dust events later in the campaign. The analyses

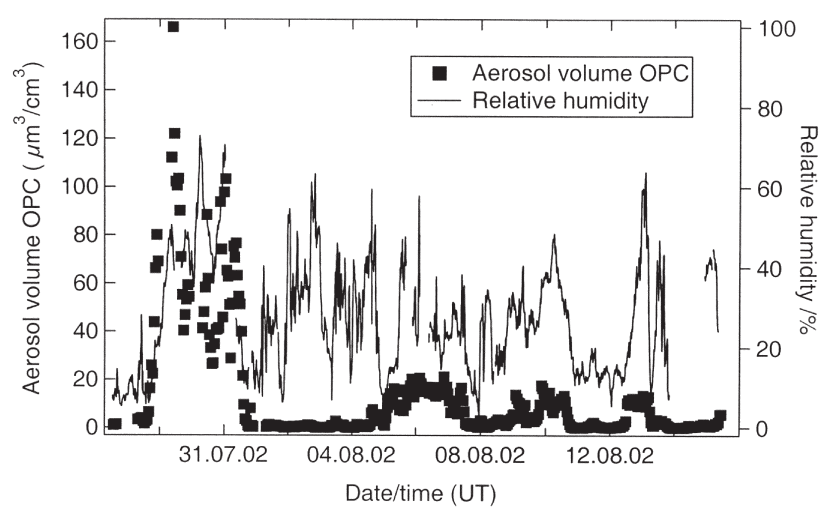

Figure 2b. Aerosol volume, as measured by an optical particle counter (OPC), and relative humidity during MINATROC. 

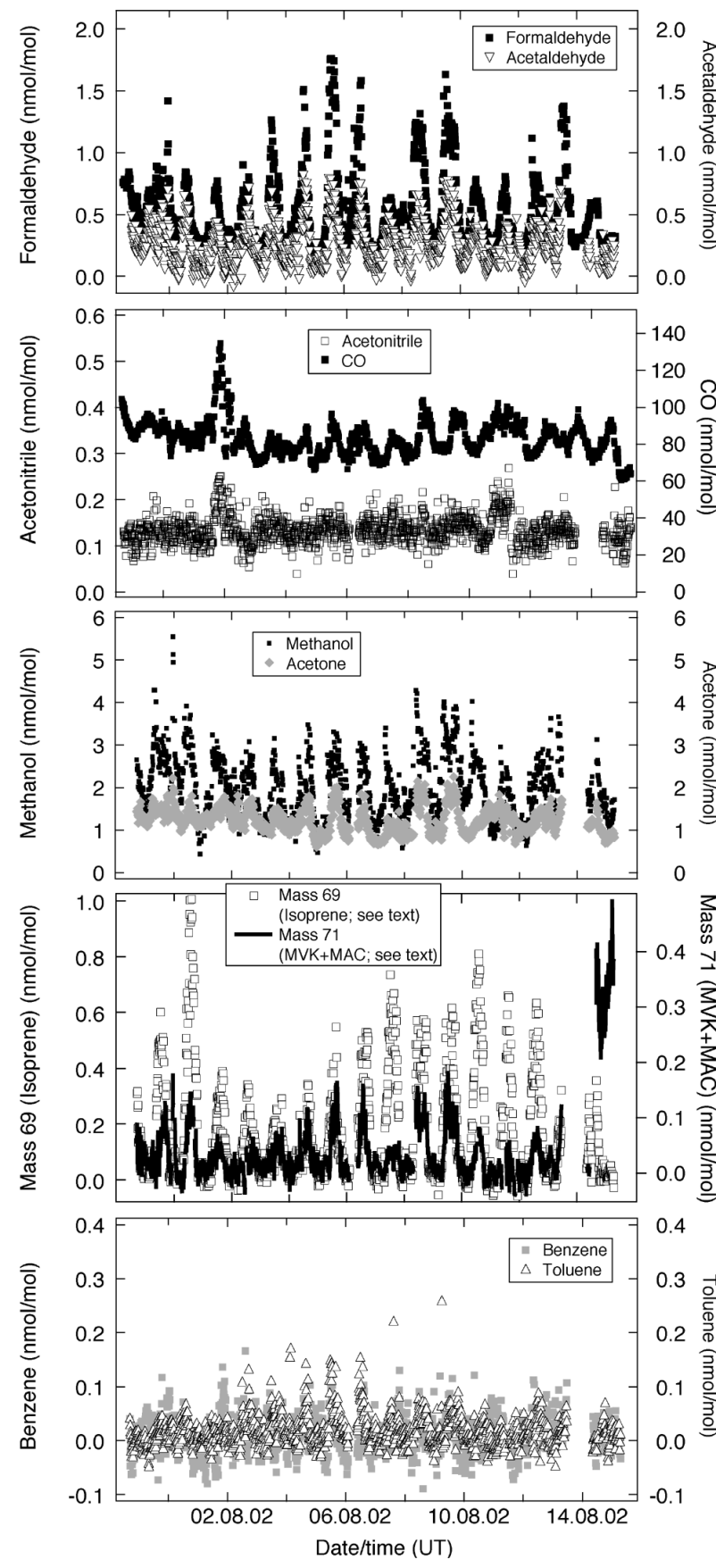

Figure 3. Time series of the identified species measured by the PTR-MS technique, as well as CO and formaldehyde, during MINATROC.

presented in this paper concentrate on a comparison between conditions during the large dust event (28-31 July) and the period after this event ( 31 July to 14 August), where both PTR-MS and canister GC-MS data were available.

[12] Time series of the positively identified species measured by the PTR-MS technique during the MINATROC campaign are shown in Figure 3. Also included in the figure are mass 69 , believed to be largely isoprene, and mass 71 , believed to consist of the sum of the isoprene oxidation products methyl vinyl ketone (MVK) and methylacrolein
(MAC), as well as $\mathrm{CO}$ and formaldehyde, measured by independent methods as described in section 3. Figure 3 shows that clear daily cycles were observed for all the PTRMS compounds except acetonitrile and benzene, owing partly to a combination of upslope conditions during the day and free tropospheric conditions at night at the measurement site. The general lack of structure in the acetonitrile time series indicates that there was little influence from biomass burning observed during most of the campaign [Lobert et al., 1990], in contrast with the outflow from Eastern Europe measured in summer 2001 [Salisbury et al., 2003]. The only exceptions to this rule were two small peaks in acetonitrile during the night on 1 and 10 11 August, which positively correlated with $\mathrm{CO}$ (see Figure 3, top panel). These features will be discussed again briefly in section 5 . The lack of a clear daily cycle for benzene was probably due to the generally low mixing ratios observed for this species, which were often around or under the PTR-MS detection limit of $44 \mathrm{pmol} / \mathrm{mol}$.

[13] Although qualitatively consistent daily cycles were observed for most of the campaign, Figure 3 also shows that the peak mixing ratios for many species were rather variable from day to day. The daytime peak in mass 69 (isoprene), for example, varied between approximately 0.3 and $1.0 \mathrm{nmol} / \mathrm{mol}$. This variability must be borne in mind in the discussion of the average daily cycles, which follows in the next section. The pronounced jump in the mixing ratios of mass 71 (generally attributed to MVK + MAC) on 14 August cannot be explained; no other PTR-MS compounds exhibited a similar pattern. Trajectory analysis showed that the air sampled at this time originated in the central Atlantic; but this was often the case during the campaign. It cannot be ruled out that another, unidentified species with protonated mass 71 was present in the air on 14 August. For this reason, this short data section was not used in calculating the mean daily cycle for mass 71 discussed in the next section.

[14] The CO, formaldehyde and acetaldehyde time series shown in Figure 3 also show pronounced daily cycles on many days, with a high degree of variability in the peak mixing ratios from day to day. Also noteworthy is the very high variability in the relative air humidity measured at the site in the course of the campaign (Figure 2b), with values ranging from virtually zero at night to up to approximately $70 \%$ during the day. The humidity was also rather variable from day to day and night to night. (It should be noted that we discuss here only the $\mathrm{CO}$, formaldehyde and relative humidity data from 29 July onward, where there were reliable PTR-MS and GC-MS data available; for further details of these measurements for the whole campaign period, see de Reus et al. [2005].

\subsection{Mixing Ratios of Organic Species at Night Under Free-Tropospheric Conditions}

[15] Table 2 shows the mean nighttime mixing ratios (i.e., under downslope, free-tropospheric conditions) of selected species measured during the MINATROC campaign at Izaña, Tenerife. (Data from the Saharan dust event are not included in these averages.) These values may be taken to be representative of the mid-Atlantic free troposphere. The oxygenated organic species are far more abundant than the measured alkanes, which is in agreement with measure- 
Table 2. Mean Nighttime Mixing Ratios of Selected Compounds at Izaña During the MINATROC Campaign (31 July to 14 August 2002)

\begin{tabular}{lcc}
\hline \multicolumn{1}{c}{ Compound } & Mean Mixing Ratio & \\
\hline $\mathrm{HO}_{2}+\mathrm{RO}_{2}$ & 6.7 & Standard Deviation $^{\mathrm{b}}$ \\
$\mathrm{Ozone}, \mathrm{nmol} / \mathrm{mol}$ & 50.5 & 2.3 \\
$\mathrm{CO}, \mathrm{nmol} / \mathrm{mol}$ & 78.2 & 14.2 \\
$\mathrm{H}_{2} \mathrm{O}_{2}, \mathrm{nmol} / \mathrm{mol}$ & 1.89 & 9.9 \\
$\mathrm{Formaldehyde,} \mathrm{nmol} / \mathrm{mol}_{\mathrm{NO}_{2}, \mathrm{nmol} / \mathrm{mol}}$ & 0.31 & 0.59 \\
$\mathrm{NO}_{\mathrm{y}}, \mathrm{nmol} / \mathrm{mol}$ & 0.12 & 0.08 \\
$\mathrm{Methanol}, \mathrm{nmol} / \mathrm{mol}$ & 0.62 & 0.04 \\
Acetonitrile, $\mathrm{nmol} / \mathrm{mol}$ & 1.40 & 0.20 \\
Acetaldehyde, $\mathrm{nmol} / \mathrm{mol}$ & 0.14 & 0.45 \\
Acetone, nmol/mol & 0.15 & 0.03 \\
Propane & 1.05 & 0.09 \\
Isobutane & 24.4 & 0.23 \\
Butane & 12.9 & 14.0 \\
Isopentane & 15.9 & 9.3 \\
Pentane & 9.0 & 36.7 \\
n-Hexane & 5.0 & 8.9 \\
Chloromethane & 2.5 & 4.6 \\
Bromomethane & 520.8 & 2.1 \\
Iodomethane & 9.5 & 43.5 \\
Chloroform & 0.2 & 0.9 \\
Dichloroethane & 10.3 & 0.1 \\
$\alpha$-Pinene & 2.2 & 17.3 \\
Camphene & 3.3 & 0.6 \\
a & 1.9 & 2.4 \\
\hline
\end{tabular}

${ }^{\mathrm{a}}$ All mixing ratios are in $\mathrm{pmol} / \mathrm{mol}$, except where indicated.

${ }^{\mathrm{b}} \mathrm{Standard}$ deviations are absolute values.

ments made over the Pacific Ocean [Singh et al., 2001]. Compared to the Pacific data set, the absolute concentrations of methanol, acetone, formaldehyde and acetaldehyde presented here are between $30 \%$ and 50\% higher; however, the relative abundances are in good agreement (i.e., methanol $>$ acetone $>$ formaldehyde $>$ acetaldehyde). The concentrations of the alkanes, both absolute and relative are also in keeping with previous studies of background air, and the general global distribution pattern [Bonsang and Boissard, 1999; Singh and Zimmerman, 1992]. The alkane measurements are in broad agreement (within a factor of 2) with measurements conducted at the same time of year at the same site in 1993 [Fischer et al., 1998]; however, we note that on average concentrations of $\mathrm{C} 4-\mathrm{C} 6$ alkanes were slightly higher in the present study and propane slightly lower. The oxygenated species were not measured in the 1993 campaign and thus cannot be compared. The nighttime CO mixing ratio in 2002 was $9 \mathrm{nmol} / \mathrm{mol}$ lower than that observed in 1993, in line with the observed CO trend of $-0.92 \pm 0.15 \mathrm{nmol} / \mathrm{mol} / \mathrm{yr}$ in the Northern Hemisphere lower troposphere [Novelli et al., 2003]. Measurements of the longer-lived organohalogen species (chloromethane and bromomethane) are also in agreement with current background estimates for these species.

\subsection{Average Daily Cycles During and After the Large Saharan Dust Event (28-31 July 2002)}

\subsubsection{General Observations}

[16] In order to compare the measurements during dusty conditions with "standard," "no-dust" conditions, mean daily cycles (15 min intervals) were calculated for the period 29-31 July (no PTR-MS data were available for 28 July) and 31 July to 14 August. Two further points must be noted at the outset of this discussion. First, as noted previously, other, smaller-scale dust events were observed during the campaign, three of which fell in the latter period. Daily cycles were therefore calculated for all species during these smaller dust events only, and compared with those for the whole period 31 July to 14 August. For each compound and quantity the daily cycles obtained were qualitatively very similar; for this reason, no further consideration has been taken in this work of the minor dust events. The second point to be made here is that the average daily cycles for the major Saharan dust event necessarily include far fewer data points than for the "standard" period. This is why the dust period daily cycles presented appear considerably more scattered than those averaged over the rest of the campaign.

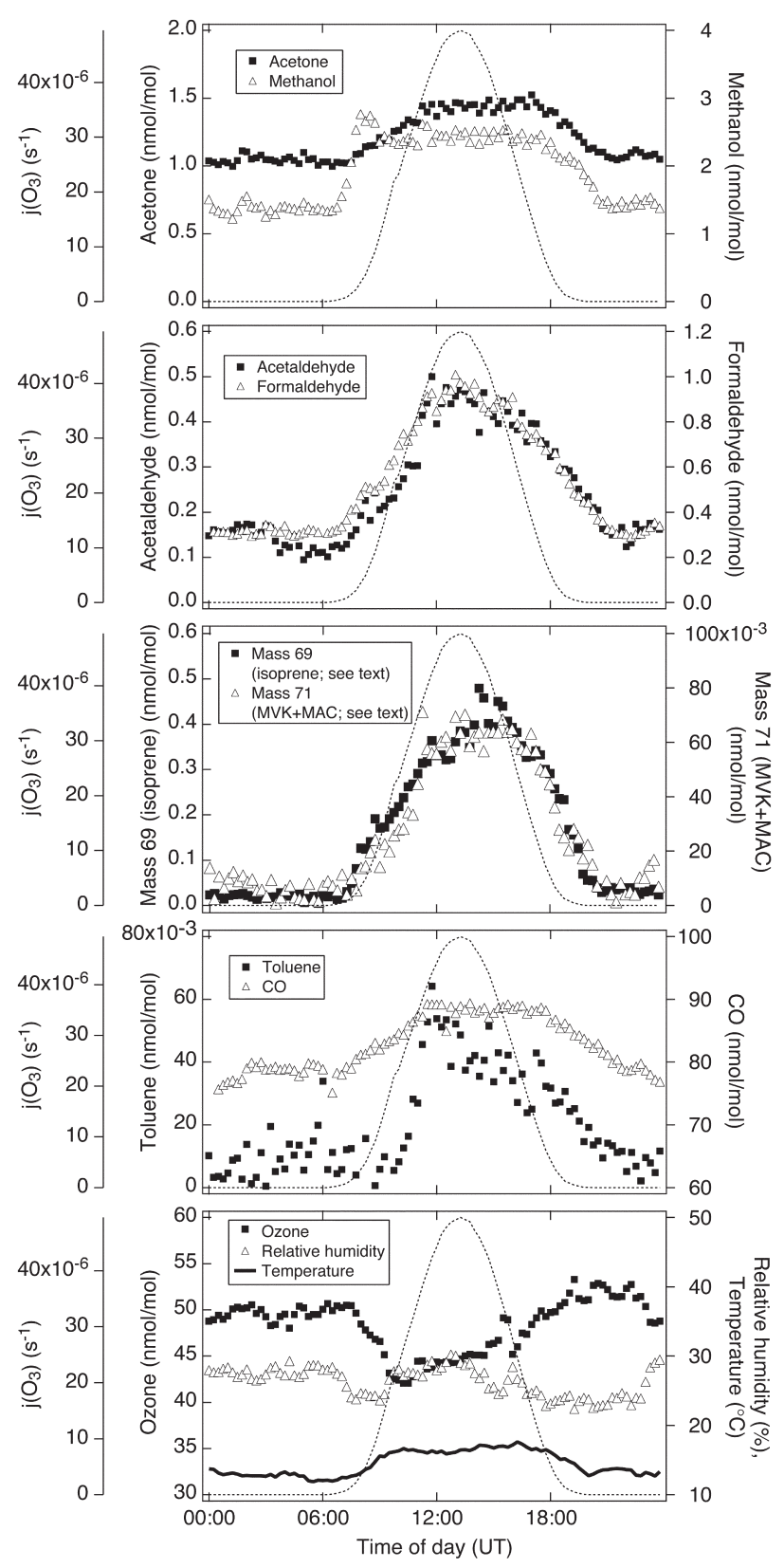

Figure 4a. Mean daily cycles for selected species during MINATROC: 31 July to 14 August. The J(O3) data are represented by the dotted lines in all plots. The detection limits and uncertainties are given in Table 1. 


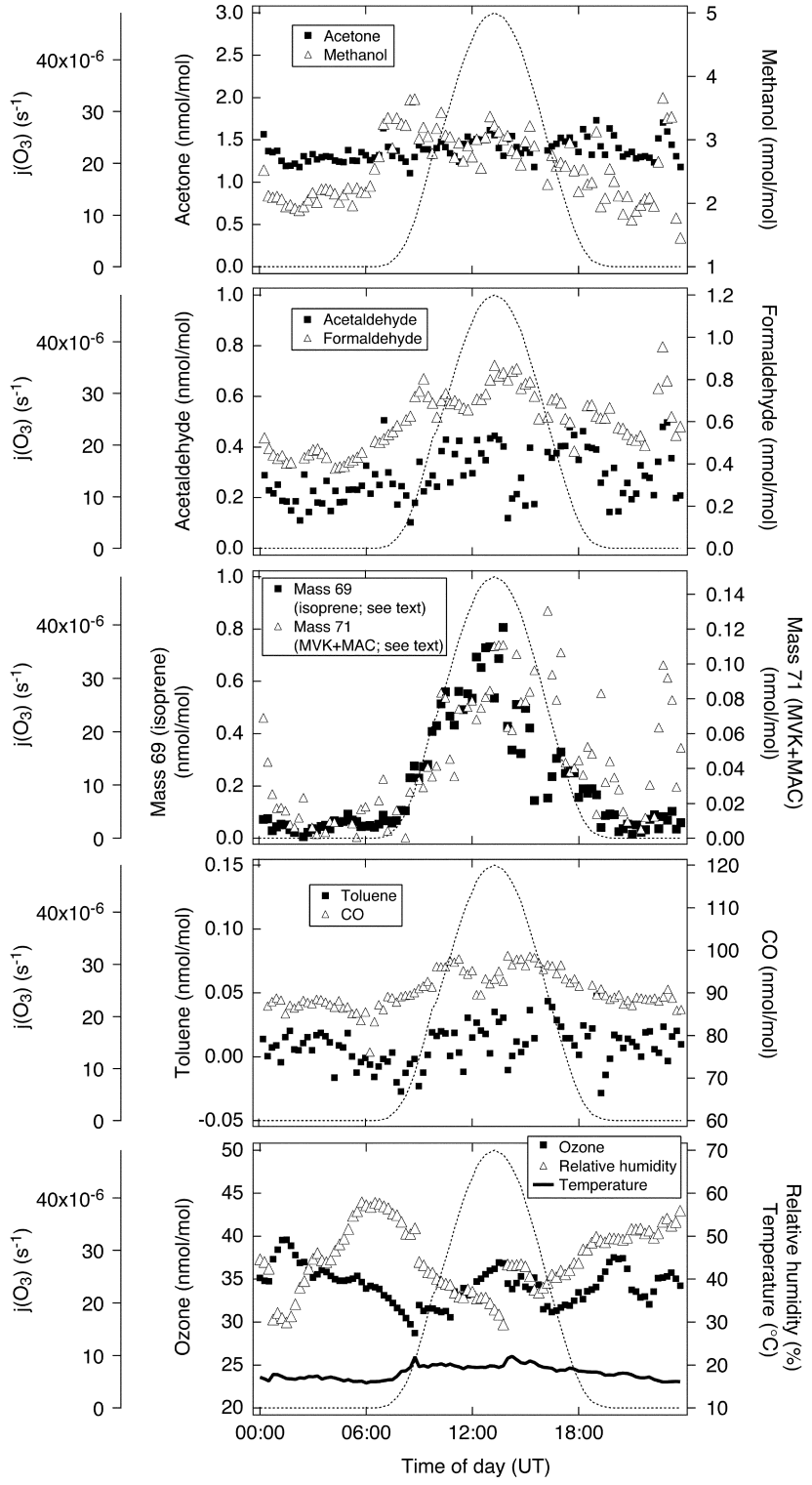

Figure $4 \mathbf{b}$. Mean daily cycles for selected species during MINATROC, during the Saharan dust event, 29-31 July. The $\mathrm{J}(\mathrm{O} 3)$ data are represented by the dotted lines in all plots. The detection limits and uncertainties are given in Table 1.

[17] Figure 4a shows the average, calculated daily cycles for methanol, acetaldehyde, acetone, mass 69 (isoprene), mass 71 (MVK + MAC), toluene, CO, formaldehyde, ozone and relative humidity during "normal" conditions (31 July to 14 August; left), and Figure 4b shows the same plots during the large Saharan dust event (29-31 July; right). Each panel includes the corresponding daily cycle of $\mathrm{J}\left(\mathrm{O}^{1} \mathrm{D}\right)$ to aid the eye.

\subsection{2. "Normal" Conditions, 31 July to 14 August}

[18] In general terms, Figure 4a shows the importance of both biogenic and anthropogenic sources of organic compounds at the Izaña site under normal conditions. Methanol, for example, shows a sudden, steep rise after sunrise, almost certainly owing to its release from leaves in the forest upwind of the measurement site as the leaf stomata open
[Galbally and Kirstine, 2002]. Mass 69, attributed to isoprene emitted from the local pine forest, but possibly also including a contribution from another biogenic compound, 2-methyl-3-buten-2-ol [Goldan et al., 1993], exhibits a pronounced, rather symmetrical peak during the daylight hours, with a maximum somewhat after local solar noon, and levels approaching zero at night. It is worth noting that the mean peak mixing ratio of mass 69 was approximately $0.4 \mathrm{nmol} / \mathrm{mol}$, which is somewhat higher than that reported for isoprene measured by GC-MS at Izaña during the OCTA campaign in the summer of 1993 (approximately $0.25 \mathrm{nmol} / \mathrm{mol}$; Fischer et al. [1998]), although the mean daily cycle in the latter work was based on only a small number of measurements (over the course of one week) at one-hourly intervals. In addition, the time series for mass 69 (Figure 3) shows that maximum mixing ratios of approximately $0.25-0.3 \mathrm{nmol} / \mathrm{mol}$ were also observed on some days in the course of the MINATROC campaign. Mass 71, attributed to the sum of the isoprene oxidation products MVK and MAC, shows a very similar daily cycle to mass 69, albeit at much lower mixing ratios (maximum approximately $60 \mathrm{pmol} / \mathrm{mol}$ ); this in itself provides further evidence that both mass identifications are correct. In short, there is no strong reason to suppose that mass 69 was not entirely attributable to isoprene during MINATROC. However, the possible presence of 2-methyl-3-buten-2-ol has been considered in the further analysis of the data presented hereafter.

[19] Anthropogenic tracers in Figure 4a include carbon monoxide and toluene. $\mathrm{CO}$ shows a steady rise in the morning and a similar rate of fall (approximately $1.5 \mathrm{nmol} / \mathrm{mol} / \mathrm{h}$ ) after about 1800 UT. During the middle of the day the average mixing ratios of $\mathrm{CO}$ are rather steady, at just under $90 \mathrm{nmol} / \mathrm{mol}$. Interestingly, acetone exhibits a very similar daily cycle (top panel of figure, correlation $\mathrm{r}=$ $0.73 \mathrm{n}=1249$ ), which suggests that local biogenic sources of acetone may be relatively unimportant at Izaña under normal conditions, as acetone typically correlates well with $\mathrm{CO}$ unless strong biogenic sources of acetone are present [de Reus et al., 2003]. The average toluene daily cycle observed is rather different, with a sharp rise in mixing ratios from about 1000 UT to around midday, followed by a steady fall for the rest of the day and throughout the evening, to very low levels during the night. The prevailing wind direction for much of the campaign was westnorthwest, i.e., from the direction of Puerto de la Cruz (population 31,830), the second largest town on Tenerife located at the coast. The toluene observations are therefore consistent with a sharp maximum in local traffic emissions in Puerto de la Cruz in the morning. The measurements also suggest that there is no clear afternoon rush hour in Puerto de la Cruz, or that the wind direction changes slightly in the afternoon so that the emissions are not experienced at Izaña. It must be noted that the peak in toluene is still very small (maximum approximately $50-60 \mathrm{pmol} / \mathrm{mol}$ ), so that the much longer lifetime of $\mathrm{CO}$ certainly means that any minor effect of local emissions on this compound's daily cycle will be submerged in the longer-range $\mathrm{CO}$ trends. In summary, the daily rise and fall in $\mathrm{CO}$ is certainly dominated by dynamics, i.e., the difference between upslope and freetropospheric conditions, and the changing boundary layer influence in the course of morning and afternoon. 
[20] Also shown in Figure 4a are the mean daily cycles of formaldehyde and acetaldehyde, which are strikingly similar. The shape of the daily profiles is reminiscent of that of toluene, with a sharp rise in the morning and a slower decay in the afternoon, but the sharp rise in both species begins straight after sunrise. The biggest difference in the two daily cycles is in the early morning, before dawn, where formaldehyde levels remain approximately constant, but acetaldehyde mixing ratios fall significantly. Acetaldehyde reacts with both $\mathrm{OH}$ and $\mathrm{NO}_{3}$ in the atmosphere at wellestablished rates [Atkinson and Arey, 2003]. Calculation showed that $1.4 \times 10^{10}$ molecules $/ \mathrm{cm}^{3}$ of $\mathrm{NO}_{3}$ or $1.7 \times$ $10^{6}$ molecules $/ \mathrm{cm}^{3}$ of $\mathrm{OH}$ would be required to produce the observed acetaldehyde loss rate of approximately $14 \mathrm{pmol} / \mathrm{mol} / \mathrm{h}$. Neither radical concentration is realistic, the former being 100 times more than previously measured $\mathrm{NO}_{3}$ concentrations at Izaña [Carslaw et al., 1997] and the later being comparable to midday $\mathrm{OH}$ measurements [e.g., Handisides et al., 2003] when the main source of $\mathrm{OH}$, namely ozone photolysis occurs and not before the sun has risen. The reason for this nighttime fall in acetaldehyde mixing ratios therefore remains unclear.

[21] The average daily cycle in ozone is also interesting. Mixing ratios of the order of $50 \mathrm{nmol} / \mathrm{mol}$ are observed at night in the free troposphere, while a sharp fall in ozone levels may be noted after sunrise, as the influence of upslope air increases. Between 1030 and 1630 UT, ozone rises again at a rate of about $1 \mathrm{nmol} / \mathrm{mol} / \mathrm{h}$; for further discussion of ozone photochemistry during MINATROC, see de Reus et al. [2005]. In the evening the cutoff between daytime upslope conditions and nighttime free-tropospheric conditions is less clear cut as in the morning, presumably because the ozone levels in the boundary layer are similar to those in the lower free troposphere at this stage of the day.

\subsubsection{Comparison Between the Daily Cycles During the Large Saharan Dust Event and Those Observed} in the Rest of the Campaign

[22] The first point to be made about the daily cycles on the right-hand side of Figure $4 \mathrm{~b}$ is that the pronounced peak in some species just before midnight was due to a single event just before midnight on 30 July, where methanol, acetone, formaldehyde, acetaldehyde, PTR-MS mass 71, and to a lesser extent, acetonitrile and $\mathrm{CO}$ were all elevated (see the time series of these species in Figure 3). Given the short lifetimes of formaldehyde and acetaldehyde, this peak was likely attributable to a short-lived, local fire, and was not therefore connected to the Saharan dust event, except that it suggests that the influence of local, boundary layer air was more important at night at this time than under normal conditions. Further evidence to support this interpretation is provided by the relative humidity daily cycle, which shows that the air sampled at Izaña was consistently moister during the dust event than at other times in the campaign $(\sim 30-$ $60 \%$, compared with $20-30 \%$ at other times). The shape of this daily cycle is also noteworthy: the relative humidity was observed to climb steadily from midafternoon to around midnight, local time, and then fall steeply until about 0200 UT. This pronounced dip was in clear anticorrelation with ozone (Figure 4a), and may represent the closest approximation to free-tropospheric conditions observed at night during the dust event. After 0200 UT the humidity rose steeply again to around sunrise, before falling once again for the entire morning period The average temperature profiles were also rather different during the dust period. The average temperatures day and night were $3^{\circ}-4^{\circ} \mathrm{C}$ higher, and the fall in temperature in the evening was also much more gradual (from about 1500 UT onward) than under normal conditions.

[23] The reduced differentiation between daytime and nighttime air masses during the dust event may also help to explain why some of the PTR-MS species exhibited similar daily cycles under Saharan dust and dust-free conditions, namely methanol, mass 69 (isoprene) and mass 71 (MVK + MAC), whereas the daily cycles of the other compounds were very different at this time (acetone, acetaldehyde and toluene). As discussed in the last section, the daily cycles of methanol, mass 69 (isoprene) and mass 71 (MVK/MAC) during MINATROC were driven largely by local biogenic emissions, which were obviously not affected by the Saharan dust event; indeed, levels of all three (four) species were on average slightly higher at this time, although this difference may not have had anything to do with the dust event per se. As noted previously, day-to-day peak mixing ratios were rather variable in any case.

[24] The remaining daily cycles shown in Figure $4 \mathrm{~b}$ (dust) are rather different from those shown in Figure 4a (normal conditions). CO levels were higher during the dust event compared to the period afterward, both day and night, and the cutoff both in the morning, and especially in the evening, between the daytime and nighttime periods was less well demarcated. In contrast, Figures $4 \mathrm{a}$ and $4 \mathrm{~b}$ also show that significantly less toluene was observed during the dust event than later in the campaign, and with a less striking daily cycle. The mean daytime NO levels during the dust event were also lower than later in the campaign. These observations taken together indicate that the air mass sampled at Izaña during the dust event was rather more polluted than those at other times, on average (higher CO), but less influenced by local pollution from Tenerife (lower NO and toluene). The latter observation is not surprising, given that the prevailing wind direction at this time was approximately from the southeast, where there is no large local town on the island.

[25] Figure $4 \mathrm{~b}$ also shows that the clear daily cycle in acetone seen during most of the campaign disappeared in the large dust event, although this effect seems unlikely to have anything directly to do with the presence of Saharan dust in the air. Again, this observation may well be a side effect of the reduced differentiation between daytime and nighttime air masses at this time: we note that daytime acetone mixing ratios were similar to at other times (approximately $1.4-1.5 \mathrm{nmol} / \mathrm{mol}$ ), but that nighttime levels were somewhat higher. Analogously to $\mathrm{CO}$, it appears that acetone is generally higher in the dust-laden air masses from the southeast.

[26] The formaldehyde and acetaldehyde daily cycles during the dust event showed a lower dynamic range (approximately 0.4 and $0.2 \mathrm{nmol} / \mathrm{mol}$, respectively) than for the rest of the campaign (approximately 0.7 and $0.4 \mathrm{nmol} / \mathrm{mol}$, respectively), with less well-defined cutoff points between day and night, as well as rather higher nighttime mixing ratios. Daytime levels of both compounds were, in contrast, slightly lower on average. Given the short lifetimes of a few hours for these species in the atmosphere, 
it would seem that the rate of production of both was higher at night but lower during the day during the dust period than at other times in the campaign. We will return to this theme in section 5 .

\section{Discussion}

[27] The discussion of this data set is divided into three parts. First we examine the data set in terms of the total reactivity presented by the organic species to $\mathrm{OH}$ during the campaign. Second the formaldehyde budget is examined in detail to better understand the changes in organic photochemistry occurring between dust and normal conditions. Finally, we assess if there is evidence for heterogeneous reactions affecting the oxygenated species, in particular acetaldehyde.

\subsection{Measured Air Reactivity (OH Sinks) During MINATROC}

[28] Using the full range of organic species measured during the MINATROC campaign, we discuss in this section the total air reactivity, or sum of organic sinks of the hydroxyl radical, under different conditions during the campaign. The total air reactivity is here defined as follows:

Air reactivity of measured species $=\Sigma k_{\mathrm{i}}\left(\mathrm{R}_{\mathrm{i}}+\mathrm{OH}\right) *\left[\mathrm{R}_{\mathrm{i}}\right]$,

where $k_{\mathrm{i}}\left(\mathrm{R}_{\mathrm{i}}+\mathrm{OH}\right)$ is the rate coefficient at measured temperature and pressure for the reaction between organic compound $\mathrm{R}_{\mathrm{i}}$ and $\mathrm{OH}$. Rate data were taken from the latest IUPAC recommendation, where available, and otherwise from the NIST database, where the latest values including temperature dependence information were always used, if such exists. The rate data for all species making a significant contribution $(>5 \%)$ to the total reactivity (see later) were available from the IUPAC recommendation, except for the terpenes $\alpha$-pinene, camphene and limonene, as measured by the 2D-GC instrument. Note that the contribution to the total reactivity of the measured alkanes $(>C 2)$ is lower than $5 \%$. Propene and butene measurements were also made from the canister samples, as described in section 3 . Laboratory tests showed, however, that the measured mixing ratios of these increased with storage time in the canisters. For this reason, the measured mixing ratios were assumed to be upper limits. On performing the reactivity calculation for these compounds, based on the daytime and nighttime average mixing ratios for the period 31 July to 14 August, it was found that the reactivity for both species together represented approximately $5 \%$ of the total reactivity during the daytime and approximately $6 \%$ during the nighttime. Because of the uncertainty in these measurements, however, they have not been included in the following discussion and are not taken into account in the total reactivity values discussed later. No account has been made of ethene or C5 or higher alkenes, where no measurements were available. In addition, no methane or ethane measurements were made during MINATROC; for this reason, methane was assigned the mixing ratio of $1800 \mathrm{nmol} / \mathrm{mol}$ throughout, whereas ethane was set to $0.5 \mathrm{nmol} / \mathrm{mol}$ at night and $0.8 \mathrm{nmol} / \mathrm{mol}$ during the daytime (as defined hereafter), on the basis of measurements made at the same site in 1993 [Fischer et al., 1998]. Total reactivity

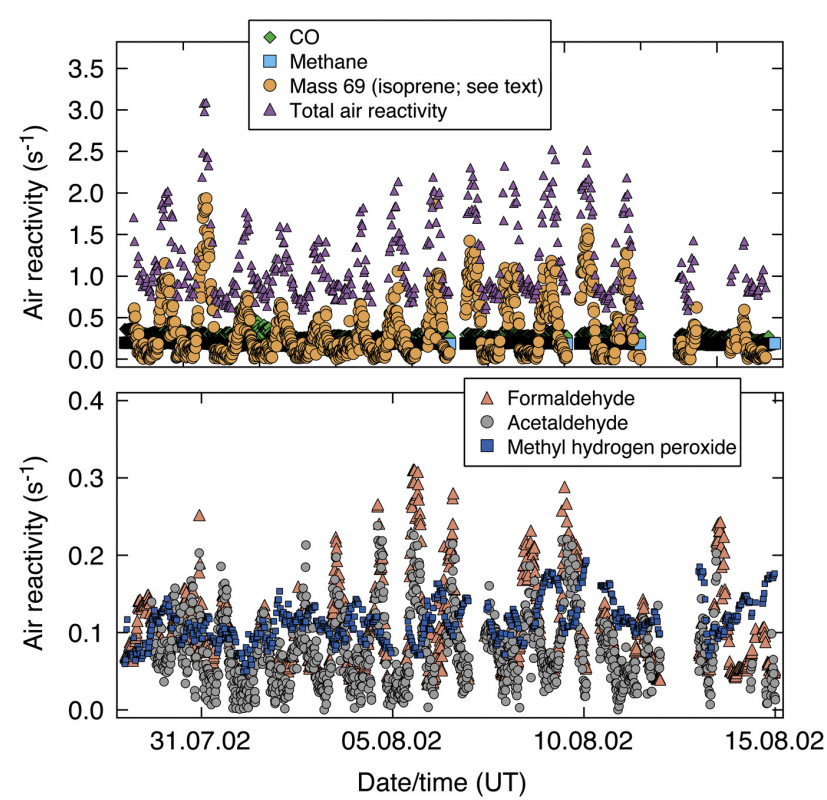

Figure 5. Time series of selected reactivity coefficients $\left(=k_{\mathrm{i}}\left(\mathrm{R}_{\mathrm{i}}+\mathrm{OH}\right) * \mathrm{R}_{\mathrm{i}},\right)$ during MINATROC.

values were only calculated where PTR-MS, formaldehyde, $\mathrm{CO}$ and estimated methyl hydrogen peroxide measurements were all available.

[29] Figure 5 shows the reactivity time series for the biggest contributors to total reactivity during MINATROC. The top panel includes CO, methane and mass 69 (isoprene), along with the total reactivity, and the bottom panel includes the oxygenated organic species formaldehyde, acetaldehyde and methyl hydrogen peroxide. As expected from the measurements of these species, large day-to-day differences were observed, as well as pronounced daily cycles for most reactivity coefficients $\left(=\mathrm{k}_{\mathrm{i}} *\left[\mathrm{R}_{\mathrm{i}}\right]\right.$ for each compound i). As the upper panel of Figure 5 shows, the major contributor to the total reactivity during the daytime was mass 69 , where we assume that the entire signal at this mass was attributable to isoprene. The peak reactivity coefficient for this component during the daytime ranged between approximately 0.6 and $1.9 \mathrm{~s}^{-1}$, which may be compared to a range in peak values for the total air reactivity of approximately $1.4-3.1 \mathrm{~s}^{-1}$. This result is in qualitative agreement with the results of Armerding et al. [1997], who concluded from offline GC measurements of isoprene that the contribution of isoprene to the total $\mathrm{OH}$ sink was at least a factor of ten larger than for any of the other nonmethane hydrocarbon (NMHC) species (C2-C6) measured at Izaña in May 1994. The other possible contributor to this mass is 2-methyl-3-buten-2-ol. However, this species is also highly reactive. On the basis of the rate measurements by Rudich et al. [1995] for the alcohol and the IUPAC recommendation for isoprene, the reactivity ratio alcohol/isoprene for the mean daytime temperature at Izaña of $16^{\circ} \mathrm{C}$ would be 0.65 , i.e., even if the entire PTR-MS signal at mass 69 were due to 2-methyl-3-buten-2-ol, this component would still represent the highest contributor to the total air reactivity during the daytime (range: approximately $0.4-1.2 \mathrm{~s}^{-1}$ ), as shown in Figure 5. 


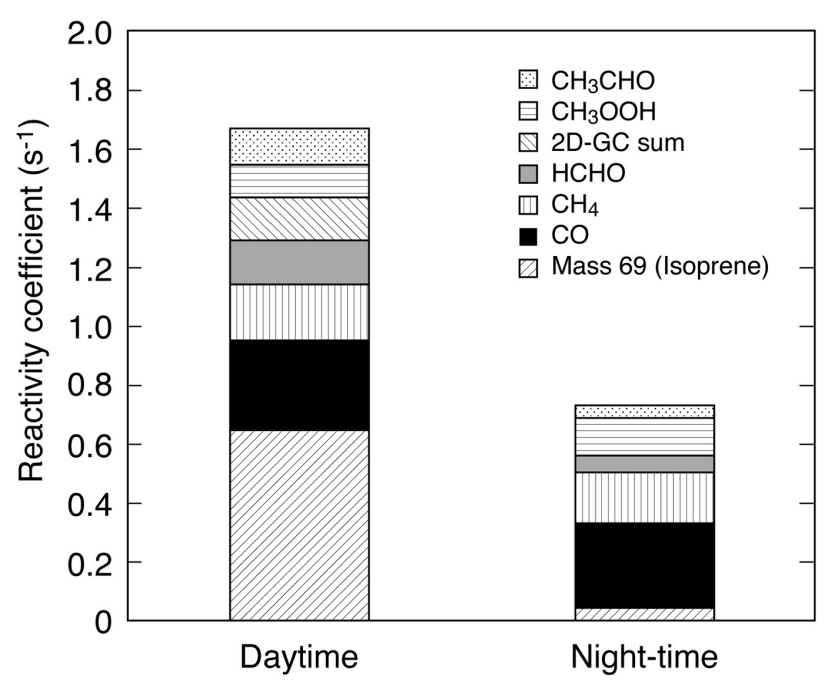

Figure 6. Contributions to total air reactivity for the period 31 July to 14 August, split into daytime (0900-1800 UT) and nighttime (2100-0600 UT) periods. Only those components contributing over $5 \%$ of the total reactivity are shown.

[30] Although the contribution of mass 69 was large, the upper panel of Figure 5 also shows that it was not the only factor in driving the total daytime air reactivity up or down. Inspection of the data in Figure 5 for 5 and 9 August, for example, shows the importance of the oxygenated species, particularly formaldehyde, but also acetaldehyde, to the total reactivity. Methyl hydrogen peroxide was also an important contributor, during the night as well as in the daytime. These points may be seen more clearly in Figure 6, which gives a breakdown of the average contributions of each compound to the total reactivity for the daytime and nighttime periods for the period 31 July to 14 August, i.e., after the Saharan dust event. (Only those compounds contributing at least $5 \%$ of the total reactivity are included, which means that the total air reactivity for each set of conditions was slightly higher than shown in Figure 6.) For the purposes of the analyses presented in this work, we define daytime as 0900-1800 UT and nighttime as 21000600 UT, in line with Fischer et al. [1998]. Figure 6 shows that, as expected, reactivity at night was dominated by $\mathrm{CO}$ and methane, although interestingly the third largest contribution was due to methyl hydrogen peroxide. It should be noted, however, that the value of methyl hydrogen peroxide is an upper limit because of the sampling method [see de Reus et al., 2005]. No significant contribution from the 2D-GC compounds (the terpenes $\alpha$-pinene, camphene and limonene) was observed at night, although some reactivity was still attributable to mass 69 (isoprene). It must be noted, however, that the mean mixing ratio of isoprene at night during this period was only $24 \mathrm{pmol} / \mathrm{mol}$, which is under the 2-sigma detection limit of the PTR-MS instrument of $46 \mathrm{pmol} / \mathrm{mol}$, based on 15-min average measurements. Figure 6 nevertheless demonstrates the importance of even trace amounts of such a reactive compound to the $\mathrm{OH}$ budget at night. Finally we note that the mean total air reactivity of the organic compounds measured for this period was $1.78 \mathrm{~s}^{-1}$ during the daytime, and $0.80 \mathrm{~s}^{-1}$ at night. The equivalent figures for the period of the Saharan dust event were slightly higher: 1.95 and $0.94 \mathrm{~s}^{-1}$, respectively (data not shown in Figure 6). For the daytime, this difference was almost entirely attributable to higher mass 69 (isoprene) mixing ratios during this short period, whereas at night mixing ratios of all of the species in Figure 6 were slightly higher than during the rest of the campaign, except those of methyl hydrogen peroxide, which were slightly lower. The general breakdown in air reactivity by compound was rather similar day and night to the rest of the campaign. In short, there is no evidence that the presence of the Saharan dust per se had any effect on the total air reactivity of the compounds measured at Izaña. As discussed previously to explain the changes in the observed daily cycles, a change in air mass and rather different local dynamics seems more likely.

[31] On the nights $1-2$ and 10-11 August, nighttime peaks of acetonitrile and $\mathrm{CO}$ were observed, as noted in section 4. However, the mean total air reactivity during these periods was 0.83 and $0.76 \mathrm{~s}^{-1}$, respectively, i.e., not significantly different from the campaign average. Clearly, these air masses represented rather aged biomass-burning plumes, where only the longest-lived fire tracers remained after transport from the burning region. For this reason, these periods are not discussed independently in detail.

\subsection{Formaldehyde Production and Loss Processes 5.2.1. Introduction and Details of the Calculations}

[32] Formaldehyde is one of the key photochemical intermediates in the chemical processing of organic species in the atmosphere. A lot of measurement and modeling effort is currently underway worldwide to try to understand the atmospheric budget of this compound, but many questions remain unanswered. During the MINATROC campaign most of the direct photochemical precursors of formaldehyde were measured directly, and methyl hydrogen peroxide could be estimated from the total peroxide measurements, as described previously. In other words, this campaign represented a rare opportunity to quantify the various chemical sources of this compound over a range of atmospheric conditions. In a separate study, de Reus et al. [2005] have applied a box model to the MINATROC data to assess the budgets of hydrogen peroxide and formaldehyde. The box model analysis approach, and the implicit steady state assumption for formaldehyde, was complicated by advection effects as well as the presence of isoprene and NOx, both of which profoundly affect the formaldehyde budget. In this work, we employ a more simple approach, assessing the source and loss terms directly from the measured data.

[33] Our calculations of formaldehyde production rates included the following $\mathrm{OH}$ reactions: methanol (yield $100 \%$, assuming $\mathrm{OH}$ attack at either carbon or oxygen gives $\mathrm{HCHO}$, via $\mathrm{CH}_{2} \mathrm{OH}$ or $\mathrm{CH}_{3} \mathrm{O}$, respectively); acetaldehyde (yield $100 \%$ to give the acetyl then the peroxy acetyl radical, which reacts further with $\mathrm{NO}$ or $\mathrm{NO}_{2}$ to give either HCHO or PAN, respectively; the PAN channel is not considered further in the calculation); acetone (to give the 


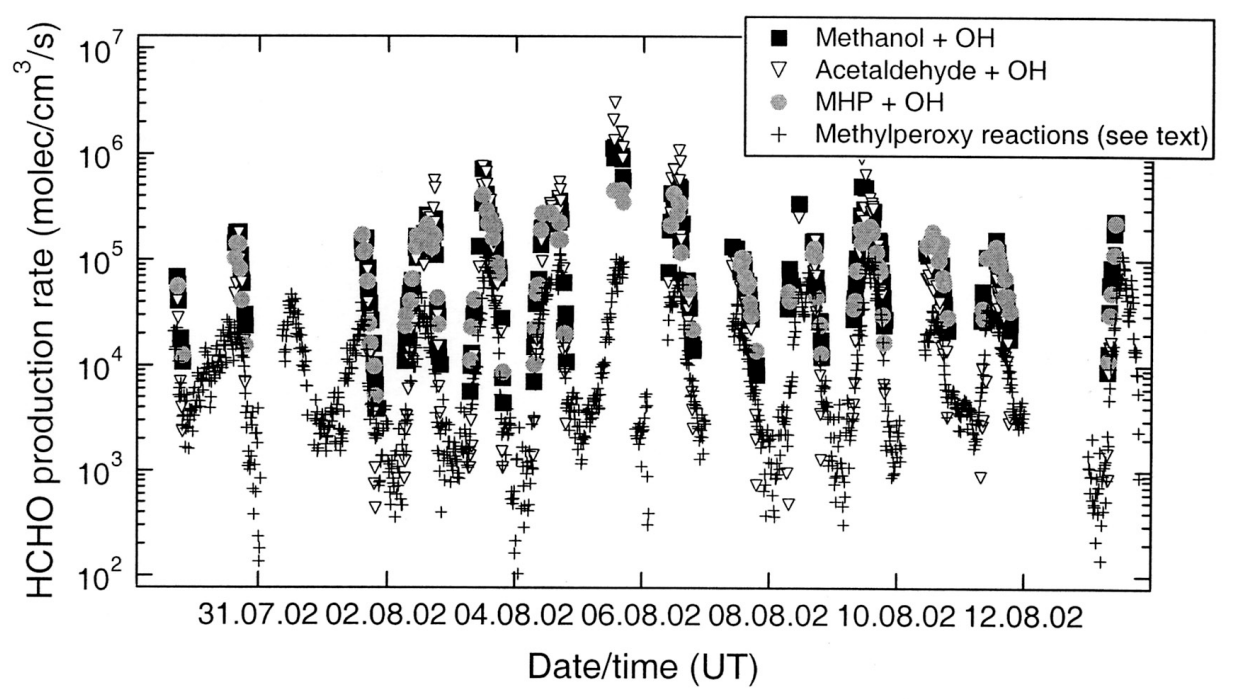

Figure 7a. Results of a rate of production analysis for formaldehyde, showing the major contributing processes: including methanol and acetaldehyde.

$\mathrm{CH}_{3} \mathrm{C}(\mathrm{O}) \mathrm{CH}_{2} \mathrm{O}_{2}$ peroxy radical, which on reaction with $\mathrm{NO}$ yields one $\mathrm{HCHO}$ molecule and one peroxy acetyl radical, which is treated as for acetaldehyde); mass 69 (assumed to be entirely isoprene, where the initial yield of $\mathrm{HCHO}$ is set to be equal to that of methyl acrolein and methyl vinyl ketone summed (0.5), based on the reaction scheme of Tuazon and Atkinson [1990b]); mass 71 (methyl acrolein and methyl vinyl ketone, where the PTR-MS signal is assumed to be divided equally between the two compounds, and an average HCHO yield of 0.19 is used [Tuazon and Atkinson, 1989, 1990a]; and methyl hydrogen peroxide (HCHO yield 0.35 , based on IUPAC recommendation). Also considered in the rate of production analysis were the photolyses of acetone (to yield $\mathrm{HCHO}$ via the peroxy acetyl radical, as described previously) and methyl hydrogen peroxide, as well as the methylperoxy self-reaction and reaction with $\mathrm{NO}$ to give $\mathrm{CH}_{3} \mathrm{O}$ and then $\mathrm{HCHO}$. For the peroxy radical reactions, three different calculations were performed, assuming that the methylperoxy radical made up 25,50 and $75 \%$ of the total peroxy radical population as measured by the PERCA technique, in order to gauge the sensitivity of the total rate of formaldehyde production to this term in the calculation. No attempt was made to quantify the possible contribution of either alkene or terpene oxidation to formaldehyde production [cf. Sumner et al., 2001], in the first case because of the lack of reliable measurements, and in the latter case because of the small amount of measurement data available and the uncertain yields of formaldehyde from these reactions.

[34] In order to be able to compare the rates of formaldehyde production from the $\mathrm{OH}$ reactions directly with the photolysis and peroxy radical routes, it was necessary to estimate $\mathrm{OH}$ concentrations during the campaign. This calculation was based on a simple steady state assumption, where the $\mathrm{OH}$ loss processes included the reactions with all measured species, including nonorganics such as ozone, $\mathrm{NO}, \mathrm{NO}_{2}$ and hydrogen peroxide, and the production processes included the photolyses of ozone, hydrogen peroxide and methyl hydrogen peroxide, and the reactions of $\mathrm{HO}_{2}$ with ozone and $\mathrm{NO}$, where $\mathrm{HO}_{2}$ was assumed to be half the total population of peroxy radicals present. The resulting maximum daytime $\mathrm{OH}$ concentrations varied between approximately $4 \times 10^{6}$ and $2.5 \times 10^{7}$ molecules $\mathrm{cm}^{-3}$; the highest values were seen when NO mixing ratios were also high (up to $0.8 \mathrm{nmol} / \mathrm{mol}$ ). The daytime average calculated $\mathrm{OH}$ concentration was $3.1 \times 10^{6}$ molecules $\mathrm{cm}^{-3}$. These results may be compared with the $\mathrm{OH}$ concentrations measured at Izaña in May 1994, where the "noontime" average $\mathrm{OH}$ concentration was 4-5 $\times$ $10^{6}$ molecules $\mathrm{cm}^{-3}$, although $\mathrm{OH}$ concentrations over $1 \times$ $10^{7}$ molecules $\mathrm{cm}^{-3}$ were also observed when NO mixing ratios were high [Armerding et al., 1997]. Given that MINATROC was a summer rather than springtime campaign, we may therefore have some confidence that the calculated $\mathrm{OH}$ concentrations used in our further analyses are reasonably realistic. For the nighttime period, a constant $\mathrm{OH}$ concentration of $5 \times 10^{4}$ molecules $\mathrm{cm}^{-3}$ was assumed, which was the average calculated concentration for late in the evening and early in the morning.

[35] In an analogous way the loss rates of formaldehyde due to $\mathrm{OH}$ attack and photolysis were calculated for purposes of comparison.

\subsubsection{Results of the Formaldehyde Rate of Production Analysis \\ 5.2.2.1. Daytime}

[36] Figures $7 \mathrm{a}$ and $7 \mathrm{~b}$ show the most important contributors to the overall calculated formaldehyde production rate, assuming that PTR-MS mass 69 was entirely isoprene, and where the methylperoxy term and the total production rate both include the assumption that $\mathrm{CH}_{3} \mathrm{O}_{2}$ represented $50 \%$ of the total peroxy radical population. All data in Figures $7 \mathrm{a}$ and $7 \mathrm{~b}$ are for the daytime period only for clarity, except the trace for the methylperoxy radicals, where all available data are included. Figure 7a shows that the reactions of methanol, acetaldehyde and methyl hydrogen peroxide (MHP) with $\mathrm{OH}$ all contributed substantially to the total, although 


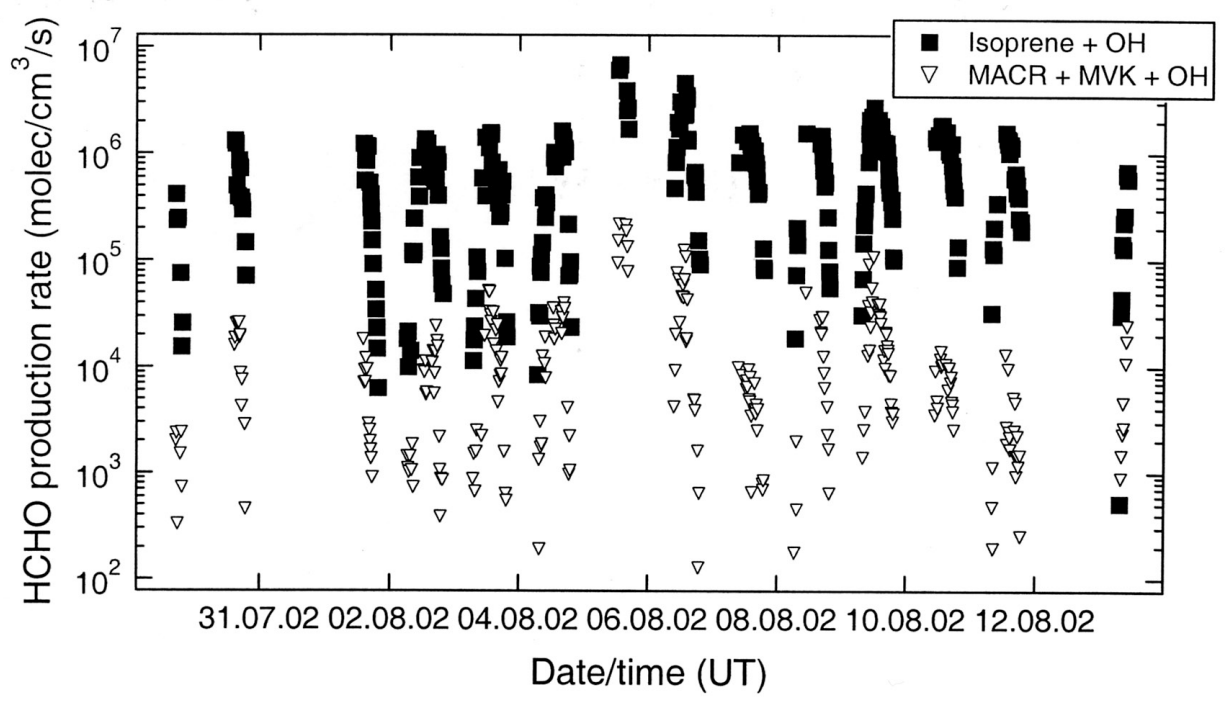

Figure 7b. Results of a rate of production analysis for formaldehyde, showing the major contributing processes: including isoprene.

their relative importance varied somewhat from day to day. The maximum formaldehyde production rate from methanol reaction exceeded $10^{6}$ molecules $/ \mathrm{cm}^{3} / \mathrm{s}$ on one day, and that from acetaldehyde on several days, whereas the maximum production rate from MHP reaction was consistently of the order of $1-5 \times 10^{5}$ molecules $/ \mathrm{cm}^{3} / \mathrm{s}$. Figure $7 \mathrm{~b}$ shows, however, that the most important daytime contributor to formaldehyde production was, as might be expected, isoprene. The rate of formaldehyde production due to isoprene reaction reached around $2 \times 10^{6}$ molecules $/ \mathrm{cm}^{3} / \mathrm{s}$ on each day where measurements were available. Of course, if there were a substantial contribution from 2-methyl-3-buten-2-ol at the PTR-MS mass 69, the results shown in Figure 7b would be somewhat different, although since this compound also contains a terminal alkene group, it would also be a significant source of formaldehyde, albeit at slightly reduced rates. Assuming a direct yield per oxidized molecule of 2-methyl-3-buten-2-ol of 0.5, as for isoprene, the rate of formaldehyde production would be approximately $16 \%$ less than shown. This possibility is considered further in the average formaldehyde production rates for the period 31 July to 14 August (after the Saharan dust event) presented in Table 3 (total A2). It must also be noted that the daytime average production rates in Table 3 are not given with standard deviations, since most of the individual terms were highly dependent on the time of day, as shown in Figures 7a and $7 \mathrm{~b}$.

[37] Figure 7c shows the high degree of linear correlation $\left(\mathrm{r}^{2}=0.91\right)$ between the total estimated daytime formaldehyde production and loss rates during MINATROC. A good correlation would of course be expected, since most of the contributory quantities are themselves highly dependent on the solar flux, but nevertheless the line of best fit for the correlation had a gradient of 0.90 , i.e., the two totals were within around $10 \%$ of each other on average, with only a relatively small intercept. This result implies that formaldehyde was in approximate photochemical balance during the daytime period, as would be expected for such a short-lived species. Table 3 shows that the average total production rate in the daytime was $2.00 \times 10^{6}$ molecules $/ \mathrm{cm}^{3} / \mathrm{s}$, which compares well to the average total loss rate of $2.22 \times 10^{6}$ molecules $/ \mathrm{cm}^{3} / \mathrm{s}$. This good general agreement between the two totals is encouraging, as it suggests that the important source reactions may all be accounted for, although it is important to consider the major sources of error inherent in the calculations. On the production side, the possible error in the isoprene term is clearly the major source of error overall, including the assumed yield of formaldehyde, and also the possibility of some contribution to the PTR-MS

Table 3. Mean Formaldehyde Production Rates During MINATROC Over the Period 31 July to 14 August 2002 (After the Large Saharan Dust Event)

\begin{tabular}{lccc}
\hline & & \multicolumn{2}{c}{ Nighttime } \\
\cline { 3 - 4 } \multicolumn{1}{c}{ Production Term } & & & \\
\cline { 3 - 4 } & Daytime Mean & Mean & Standard Deviation \\
\hline Methanol + OH & $1.85 \times 10^{5}$ & $1.16 \times 10^{3}$ & $3.22 \times 10^{2}$ \\
Acetaldehyde + OH & $2.34 \times 10^{5}$ & $3.44 \times 10^{1}$ & $9.12 \times 10^{1}$ \\
Acetone + OH & $2.81 \times 10^{4}$ & $1.66 \times 10^{2}$ & $3.82 \times 10^{1}$ \\
Isoprene + OH & $1.22 \times 10^{6}$ & $1.31 \times 10^{3}$ & $1.51 \times 10^{3}$ \\
MVK + MAC) + OH & $2.22 \times 10^{4}$ & $1.42 \times 10^{2}$ & $3.64 \times 10^{2}$ \\
MHP + OH & $1.54 \times 10^{5}$ & $2.18 \times 10^{3}$ & $5.57 \times 10^{2}$ \\
Acetone photolysis & $7.76 \times 10^{3}$ & - & - \\
MHP photolysis & $1.14 \times 10^{5}$ & - & - \\
Methylperoxy A & $3.54 \times 10^{4}$ & $2.10 \times 10^{3}$ & $1.36 \times 10^{3}$ \\
Methylperoxy B & $7.96 \times 10^{4}$ & $4.72 \times 10^{3}$ & $3.07 \times 10^{3}$ \\
Methylperoxy C & $8.85 \times 10^{3}$ & $5.25 \times 10^{2}$ & $3.41 \times 10^{2}$ \\
Total Production A & $2.00 \times 10^{6}$ & $7.10 \times 10^{3}$ & - \\
Total A2 & $1.67 \times 10^{6}$ & $6.64 \times 10^{3}$ & - \\
Total B & $2.05 \times 10^{6}$ & $9.72 \times 10^{3}$ & - \\
Total C & $1.98 \times 10^{6}$ & $5.52 \times 10^{3}$ & - \\
Loss term & & & - \\
$\quad$ OH & $7.88 \times 10^{5}$ & $2.80 \times 10^{3}$ & $7.52 \times 10^{2}$ \\
Photolysis & $1.43 \times 10^{6}$ & - & - \\
$\quad$ Total loss & $2.22 \times 10^{6}$ & $2.80 \times 10^{3}$ & $7.52 \times 10^{2}$ \\
\hline
\end{tabular}

${ }^{\mathrm{a}}$ All rates are in molecules $/ \mathrm{cm}^{3} / \mathrm{s}$. Letters $\mathrm{A}, \mathrm{B}$, and $\mathrm{C}$ refer to the assumed fraction of the methylperoxy radical in total $\mathrm{HO}_{2}+\mathrm{RO}_{2}: \mathrm{A}=0.5$, $\mathrm{B}=0.25$, and $\mathrm{C}=0.75$. Total $\mathrm{A} 2$ assumes fraction 0.5 methylperoxy but replaces isoprene with 2-methyl-3-buten-2-ol (see text). 


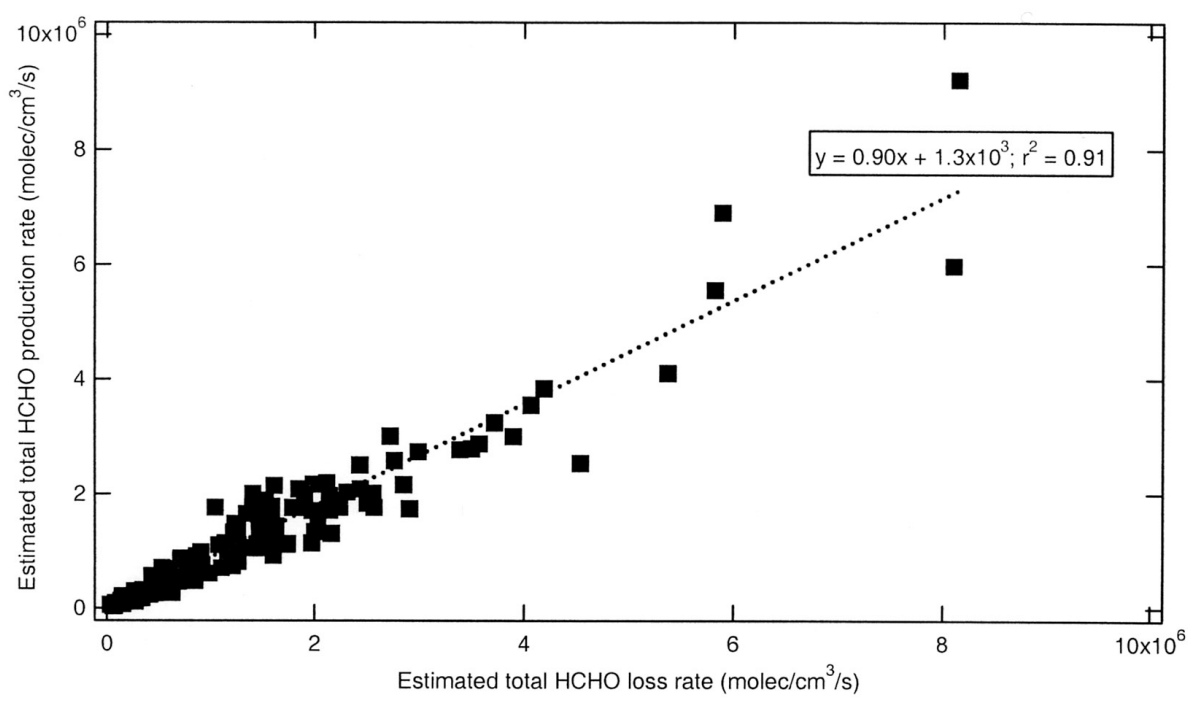

Figure 7c. A correlation plot between total estimated formaldehyde production and loss rates.

mass 69 from 2-methyl-3-buten-2-ol (see total term A2 in Table 3). Moreover, acetaldehyde, the second most important formaldehyde source, is subject to some measurement uncertainty (see section 3). Errors in the calculated $\mathrm{OH}$ concentrations are also important to bear in mind, since $\mathrm{OH}$ reactions accounted for around $95 \%$ of the production processes and only approximately $35 \%$ of the loss processes, on average (Table 3). If $\mathrm{OH}$ were overestimated, for example, the calculated formaldehyde production rate would be artificially high compared to the total estimated loss rate. We also note that no account has been made here of dry deposition of formaldehyde or its precursors, which may have an important impact on the budget of formaldehyde both day and night, but is rather hard to account for during daytime, upslope conditions. If this term were important, it would imply that our calculated formaldehyde production rates are too low. This might be partly due to missing sources from unmeasured alkenes, or perhaps more likely to an underestimate of the formaldehyde yield from isoprene oxidation.

[38] The methylperoxy term (Figure 7a) was of course very sensitive to the methylperoxy radical concentrations assumed, although the concomitant change in the total formaldehyde production rate during the daytime was relatively small $(<10 \%$, on average; see total terms $\mathrm{A}$, B, and $\mathrm{C}$ in Table 3 ), and is therefore not discussed further here. The other major contributor to daytime formaldehyde production was found to be the photolysis of MHP (see Figure $7 b$ ).

[39] The daytime average formaldehyde production and loss rates during the Saharan dust event (data included in Figures $7 a-7 c$, but averages not included in Table 3) were both consistently lower for all source species than for the rest of the campaign. The total average production rate was calculated to be $1.00 \times 10^{6}$ molecules $/ \mathrm{cm}^{3} / \mathrm{s}$ and the average total loss rate was $1.35 \times 10^{6}$ molecules $/ \mathrm{cm}^{3} / \mathrm{s}$. These results would imply that local photochemistry at Izaña was somewhat suppressed during the large dust event.
Further evidence for this conclusion is provided by the fact that the average daytime calculated $\mathrm{OH}$ concentration for this period was lower $\left(1.72 \times 10^{6}\right.$ molecules $\left./ \mathrm{cm}^{3}\right)$ than for the rest of the campaign $\left(3.21 \times 10^{6}\right.$ molecules $\left./ \mathrm{cm}^{3}\right)$, although peak $\mathrm{J}\left(\mathrm{O}^{1} \mathrm{D}\right)$ values were virtually identical, on average $(<1 \%$ difference).

\subsubsection{Nighttime}

[40] At night the situation was clearly very different, with the methylperoxy radical reactions taking on more importance, so that the assumed proportion of this species in the total peroxy radical population became more critical. Altering the proportion of methylperoxy present from 0.5 to 0.75 and 0.25 made about $35 \%$ difference to the total formaldehyde production rate in each case, and this effect could be even greater if nighttime $\mathrm{OH}$ were really lower than the calculated value of $5 \times 10^{4}$ molecules $/ \mathrm{cm}^{3}$. The right-hand column of Table 3 also shows that even very small amounts of either isoprene or 2-methyl-3-buten-2-ol present at night would contribute significantly to the total formaldehyde production. However, even if this contribution were neglected completely, Table 3 indicates that the average sum of the production processes still far exceeded the total loss rate of formaldehyde at night: in this case the estimated total production rate would be $5.79 \times 10^{3}$ molecules $/ \mathrm{cm}^{3}$, compared with a total loss rate of $2.80 \times 10^{3}$ molecules $/ \mathrm{cm}^{3}$. The mean daily cycle of formaldehyde shown in Figure $4 \mathrm{a}$ indicates that the nighttime mixing ratios of formaldehyde during MINATROC were quite constant, at around $0.3 \mathrm{nmol} / \mathrm{mol}$, which implies that the average production and loss rates during the night should be comparable, i.e., it seems likely that we have neglected one or more important nighttime loss processes. The calculations thus far assume that the only loss process of formaldehyde at night was reaction with $\mathrm{OH}$. However, other possibilities not included in Table 3 are reaction with the $\mathrm{NO}_{3}$ radical and dry deposition. (Wet deposition can be excluded, since no rain fell at the site during the campaign period). 
[41] If $\mathrm{NO}_{3}$ reaction alone were responsible for the deficit shown in Table 3, calculation showed that approximately $79 \mathrm{pmol} / \mathrm{mol} \mathrm{NO}_{3}$ would be required to provide the requisite balancing loss rate, or $55 \mathrm{pmol} / \mathrm{mol}$ if the contribution of mass 69 to formaldehyde production at night were neglected. Carslaw et al. [1997], in contrast, measured only up to approximately $20 \mathrm{pmol} / \mathrm{mol} \mathrm{NO}_{3}$ at Izaña in May 1994. This suggests in turn that the bulk of the missing loss rate might be due to dry deposition. Assuming no contribution by $\mathrm{NO}_{3}$ chemistry, and using an average nighttime mixing ratio for $\mathrm{HCHO}$ of $0.3 \mathrm{nmol} / \mathrm{mol}$ (Table 2), and a mixing height of $9700 \mathrm{~m}$ (given an estimated tropopause height of $12,000 \mathrm{~m}$ and allowing for the height of the measurement site), we calculate the dry deposition velocity of formaldehyde at night for Izaña to be $0.74 \mathrm{~cm} / \mathrm{s}$, which compares reasonably well with the results of Sumner et al. [2001], who calculated a value of $0.65 \mathrm{~cm} / \mathrm{s}$, although this value was for a forested site. Ayers et al. [1997] adopted a slightly lower value of $0.5 \mathrm{~cm} / \mathrm{s}$ for the formaldehyde deposition velocity at Cape Grim, a marine boundary layer site on the northwest tip of Tasmania, where this value was chosen to best match the overnight formaldehyde decay rate in a box model. These calculations are therefore consistent with the conclusion that the "missing" loss term shown in Table 3 may be largely accounted for by dry deposition, but with a probable small contribution from the $\mathrm{HCHO}-\mathrm{NO}_{3}$ reaction.

[42] In contrast with the daytime situation, a comparison with the Saharan dust event showed that formaldehyde production and loss rates were on average higher at night during the latter period than during the rest of the campaign, owing in this case to the slightly higher mixing ratios of most of the source species at night $(\mathrm{OH}$ was assumed constant, as noted previously). For the dust event, the total average production and loss rates were estimated to be $9.71 \times 10^{3}$ molecules $/ \mathrm{cm}^{3} / \mathrm{s}$ and $4.28 \times 10^{3}$ molecules $/ \mathrm{cm}^{3} / \mathrm{s}$, respectively. The deficit between calculated production and loss rates was therefore also evident during this period.

\subsection{Evidence for Dust-Related Production or Loss of Oxygenated Organic Species?}

[43] In this section we assess whether there is evidence of clear dust-related effects for methanol, acetone, formaldehyde and acetaldehyde. From Figures $4 \mathrm{a}$ and $4 \mathrm{~b}$ it can be seen that the daily cycle of methanol is not significantly different within the dust period than under normal conditions. The early morning peak is evidence of local emissions from the forest encircling the island from sea level to $1.8 \mathrm{~km}$. Nighttime methanol levels at Izaña are around $0.75 \mathrm{nmol} / \mathrm{mol}$ slightly lower than measurements made in the tropical Atlantic marine boundary layer (approximately $1 \mathrm{nmol} / \mathrm{mol}$ ) in October of the same year [Williams et al., 2004]. This data set therefore provides no compelling evidence that methanol is strongly affected by the presence of dust, by either a heterogeneous production or loss. The same is true of acetone. Increases in the nighttime mixing ratios of acetone during the dust event can be attributed to generally higher pollution levels that are also seen in $\mathrm{CO}$. It was noted by de Reus et al. [2003] that CO and acetone are generally well correlated in the atmosphere, with a ratio of 21-25 pmol/mol of acetone per $\mathrm{nmol} / \mathrm{mol}$ of $\mathrm{CO}$. The increases observed in the nighttime during the dust event correspond exactly to this ratio, indicating that the dust was suspended in air richer in acetone and $\mathrm{CO}$ than from the prevailing westerly wind direction.

[44] In the dust-free period the daily cycle of acetaldehyde closely follows formaldehyde; see Figure 4a. Both are photochemical products of hydrocarbon oxidation, and direct biogenic emissions and both have relatively short atmospheric lifetimes (1-2 days). Compared to the dust-free period, acetaldehyde levels in the dust storm are higher by night and lower by day. The higher values at night could be the result of generally higher levels of pollution in the free troposphere at the time of the dust event, as with acetone above. However, since the photochemical lifetime of acetaldehyde is short, this implies production is occurring in the polluted but aged air mass. That ethyl radicals and therefore acetaldehyde can be produced photochemically from many species has been shown previously in studies of alkyl nitrates [Roberts et al., 1998]. A nighttime heterogeneous production mechanism involving dust cannot, however, be ruled out. During the day the absolute levels of acetaldehyde are, like those of formaldehyde, lower in the dust event. This suggests that a significant production mechanism for acetaldehyde or formaldehyde on dust is unlikely.

\section{Conclusions}

[45] The Izaña field site has been characterized for organic species in July-August 2002. In terms of absolute concentration, the oxygenated species dominate over the alkanes. The mixing ratios of the organic species (section 4.2) and the air reactivity coefficients (section 5.1) calculated for the nighttime period should also be representative of the midAtlantic free troposphere. Of course, $\mathrm{OH}$ is very low at night under these conditions, but the importance of these results lies in the fact that the total $\mathrm{OH}$ sink available will be the same during the daytime in the free troposphere.

[46] The formaldehyde rate-of-production analysis (see Figures $7 \mathrm{a}$ and $7 \mathrm{~b}$ and Table 3) showed the importance of local biogenic sources of this species at Izaña, whether or not one believes that the entire PTR-MS signal at mass 69 was due to isoprene. Of the other important precursors to formaldehyde, methanol is also believed to be mainly a biogenically emitted species [Galbally and Kirstine, 2002], and the daily cycles of this compound (Figure 4) at Izaña support this hypothesis. The remaining three important processes producing formaldehyde involved two further organic compounds: the reactions of $\mathrm{OH}$ with acetaldehyde and methyl hydrogen peroxide, and also the photolysis of the latter species. Acetaldehyde may often largely be a secondary photochemical product, with a number of different possible sources, although it is also directly emitted from vegetation [e.g., Kesselmeier et al., 1997], and methyl hydrogen peroxide is produced solely through the reaction of $\mathrm{HO}_{2}$ and $\mathrm{CH}_{3} \mathrm{O}_{2}$. Both these compounds are therefore in themselves good indicators of local photochemical activity, although it cannot easily be said to what extent they are biogenic or anthropogenic products.

[47] The differences in average formaldehyde production and loss rates between the Saharan dust event and the rest of the campaign, as described at the end of section 5.2, are suggestive, but it must be stressed that the comparison is not 
between two closely similar air masses, one with a burden of Saharan dust, the other not. For example, the CO daily cycles for the two periods (Figure 4) were rather different, with generally higher $\mathrm{CO}$ (and acetone) mixing ratios observed night and day during the Saharan dust event compared with the rest of the campaign on average.

[48] No clear production on dust could be ascertained from measurements of the oxygenated compounds methanol, formaldehyde, acetone and acetaldehyde. In summary, it probably requires a larger field data set with many more dust events than the single one provided by MINATROC, as well as further laboratory investigations, to distinguish any more subtle chemical effects of Saharan dust on the atmospheric chemistry of the oxygenated organic species.

[49] Acknowledgments. The Max Planck Institute engineers T. Klüpfel, R. Hofmann, R. Königstedt, and U. Parchatka are thanked for their assistance in the preparation and operation of the instruments used in this campaign. R. van Dingenen is thanked for providing the OPC data. Emilio Cuevas is acknowledged for cooperation and advice regarding the Izaña field measurement site.

\section{References}

Apel, E. C., A. J. Hills, R. Lueb, S. Zindel, S. Eisele, and D. D. Riemer (2003), A fast-GC/MS system to measure $\mathrm{C}_{2}$ to $\mathrm{C}_{4}$ carbonyls and methanol aboard aircraft, J. Geophys. Res., 108(D20), 8794, doi:10.1029/ 2002JD003199.

Armerding, W., et al. (1997), Testing the daytime oxidizing capacity of the troposphere: $1994 \mathrm{OH}$ field campaign at the Izaña Observatory, Tenerife, J. Geophys. Res., 102, 10,603-10,611.

Atkinson, R., and J. Arey (2003), Atmospheric degradation of volatile organic compounds, Chem. Rev. Washington D.C., 103(12), 4605-4638

Ayers, G. P., R. W. Gillett, H. Granek, C. de Serves, and R. A. Cox (1997), Formaldehyde production in clean marine air, Geophys. Res. Lett., 24 $401-404$.

Bian, H., and C. S. Zender (2003), Mineral dust and global tropospheric chemistry: Relative roles of photolysis and heterogeneous uptake, J. Geophys. Res., 108(D21), 4672, doi:10.1029/2002JD003143.

Bonasoni, P., P. Cristofanelli, F. Calzolari, U. Bonafe, F. Evangelisti, A.Stohl, S. Z. Sajani, R. van Dingenen, T. Colombo, and Y. Balkansk (2004), Aerosol-ozone correlations during dust transport episodes, Atmos. Chem. Phys., 4, 1201-1215.

Bonsang, B., and C. Boissard (1999), Global distribution of reactive hydrocarbons in the atmosphere, in Reactive Hydrocarbons in the Atmosphere, edited by N. Hewitt, pp. 209-265, Elsevier, New York.

Carslaw, N., J. M. C. Plane, H. Coe, and E. Cuevas (1997), Observations of the nitrate radical in the free troposphere at Izaña de Tenerife, J. Geophys. Res., 102, 10,613-10,622.

Dentener, F. J., G. R. Carmichael, Y. Zhang, J. Lelieveld, and P. J. Crutzen (1996), Role of mineral aerosol as a reactive surface in the global troposphere, J. Geophys. Res., 101, 22,869-22,889.

de Reus, M., F. Dentener, A. Thomas, S. Borrmann, J. Ström, and J. Lelieveld (2000), Airborne observations of dust aerosol over the North Atlantic Ocean during ACE-2: Indications for heterogeneous ozone destruction, J. Geophys. Res., 105, 15,263-15,275.

de Reus, M., H. Fischer, F. Arnold, J. de Gouw, C. Warneke, and J. Williams (2003), On the relationship between acetone and carbon monoxide in different airmasses, Atmos. Chem. Phys., 3, 1709-1723.

de Reus, M., H. Fischer, R. Sander, V. Gros, R. Kormann, G. Salisbury, R. van Dingenen, J. Williams, M. Zollner, and J. Lelieveld (2005), Observations and model calculations of trace gas scavenging in a dense Saharan dust plume during MINATROC, Atmos. Chem. Phys., 5, 1787-1803.

Fischer, H., et al. (1998), Trace gas measurements during the Oxidizing Capacity of the Tropospheric Atmosphere campaign 1993 at Izaña, J. Geophys. Res., 103, 13,505-13,518.

Fischer, H., et al. (2003), Ozone production and trace gas correlations during the June 2000 MINATROC intensive measurement campaign at Mt. Cimone, Atmos. Chem. Phys., 3, 725-738.

Galbally, I. E., and W. Kirstine (2002), The production of methanol by flowering plants and the global cycle of methanol, J. Atmos. Chem., 43, 195-229.

Goldan, P. D., W. C. Kuster, F. C. Fehsenfeld, and S. A. Montzka (1993), The observation of a $\mathrm{C}_{5}$ alcohol emission in a North American pine forest, Geophys. Res. Lett., 20, 1039-1042.
Gros, V., et al. (2003), Origin of anthropogenic hydrocarbons and halocarbons measured in the summertime european outflow (on Crete in 2001), Atmos. Chem. Phys., 3, 1223-1235.

Handisides, G. M., C. Plass-Dulmer, S. Gilge, H. Bingemer, and H. Berresheim (2003), Hohenpeissenberg Photochemical Experiment (HOPE 2000), Measurements and photostationary state calculations of $\mathrm{OH}$ and peroxy radicals, Atmos. Chem. Phys., 3, 1565-1588.

Hanke, M., B. Umann, J. Ueker, F. Arnold, and H. Bunz (2003), Atmospheric measurements of gas-phase $\mathrm{HNO}_{3}$ and $\mathrm{SO}_{2}$ using chemical ionization mass spectrometry during the MINATROC field campaign 2000 on Mont Cimone, Atmos. Chem. Phys., 3, 417-436.

Heikes, B. G., et al. (2002), Atmospheric methanol budget and ocean implication, Global Biogeochem. Cycles, 16(4), 1133, doi:10.1029/ 2002GB001895

Jacob, D. J., B. D. Field, E. M. Jin, I. Bey, Q. B. Li, J. A. Logan, R. M. Yantosca, and H. B. Singh (2002), Atmospheric budget of acetone, J. Geophys. Res., 107(D10), 4100, doi:10.1029/2001JD000694.

Jaegle, L., D. J. Jacob, W. H. Brune, and P. O. Wennberg (2001), Chemistry of $\mathrm{HO}_{\mathrm{x}}$ radicals in the upper troposphere, Atmos. Environ., 35, 469-489.

Kaufman, Y. J., I. Koren, L. A. Remer, D. Tanré, P. Ginoux, and S. Fan (2005), Dust transport and deposition observed from the Terra-Moderate Resolution Imaging Spectroradiaometer (MODIS) spacecraft over the Atlantic Ocean, J. Geophys. Res., 110, D10S12, doi:10.1029/ 2003 JD004436.

Kesselmeier, J., et al. (1997), Emission of short chained organic acids, aldehydes and monoterpenes from Quercus ilex L. and Pinus pinea L. in relation to physiological activities, carbon budget and emission algorithms, Atmos. Environ., 31, 119-133.

Kormann, R., et al. (2003), Formaldehyde over the eastern Mediterranean during MINOS: Comparison of airborne in-situ measurements with 3D-model results, Atmos. Phys. Chem., 3, 851-861.

Lewis, A. C., J. R. Hopkins, L. J. Carpenter, J. Stanton, K. A. Read, and M. J. Pilling (2005), Sources and sinks of acetone, methanol, and acetaldehyde in North Atlantic marine air, Atmos. Chem. Phys., 5, $1963-1974$

Lindinger, W., A. Hansel, and A. Jordan (1998), Proton-transfer-reaction mass spectrometry (PTR-MS): On-line monitoring of volatile organic compounds at pptv levels, Chem. Soc. Rev., 27(5), 347-354.

Lobert, J. M., D. H. Scharffe, W. M. Hao, and P. J. Crutzen (1990), Importance of biomass burning in the atmospheric budgets of nitrogencontaining gases, Nature, 346, 552-554.

Maring, H., D. L. Savoie, M. A. Izaguirre, C. McCormick, R. Arimoto, J. M. Prospero, and C. Pilinis (2000), Aerosol physical and optica properties and their relationship to aerosol composition in the free troposphere at Izana, Tenerife, Canary Islands during July 1995, J. Geophys. Res., 105, 14,677-14,700.

Martin, R. V., D. J. Jacob, R. M. Yantosca, M. Chin, and P. Ginoux (2003), Global and regional decreases in tropospheric oxidants from photochemical effects of aerosols, J. Geophys. Res., 108(D3), 4097, doi:10.1029/ 2002JD002622.

McKeen, S. A., T. Gierczak, J. B. Burkholder, P. O. Wennberg, T. F. Hanisco, E. R. Keim, R. S. Gao, S. C. Liu, A. R. Ravishankara, and D. W. Fahey (1997), The photochemistry of acetone in the upper troposphere: A source of odd-hydrogen radicals, Geophys. Res. Lett., 24, $3177-3180$

Northway, M. J., J. A. de Gouw, D. W. Fahey, R. S. Gao, C. Warneke, J. M. Roberts, and F. Flocke (2004), Evaluation of the role of heterogeneous oxidation of alkenes in the detection of atmospheric acetaldehyde, Atmos. Environ., 38, 6017-6028.

Novelli, P. C., K. A. Masarie, P. M. Lang, B. D. Hall, R. C. Myers, and J. W. Elkins (2003), Reanalysis of tropospheric CO trends: Effects of the 1997-1998 wildfires, J. Geophys. Res., 108(D15), 4464, doi:10.1029/ 2002JD003031.

Putaud, J. P., et al. (1999), Chemical mass closure and origin assessment of the submicron aerosol in the marine boundary layer and the free troposphere at Tenerife during ACE-2, Tellus, Ser B, 52, 141-168.

Roberts, J. M., S. B. Bertman, D. D. Parrish, F. C. Fehsenfeld, B. T. Jobson, and H. Niki (1998), Measurement of alkyl nitrates at Chebogue Point, Nova Scotia during the 1993 North Atlantic Regional Experiment (NARE) intensive, J. Geophys. Res., 103, 13,569-13,580.

Rudich, Y., R. Talukdar, J. B. Burkholder, and A. R. Ravishankara (1995), Reaction of methylbutenol with hydroxyl radical: Mechanism and atmospheric implications, J. Phys. Chem., 99, 12,188-12,199.

Salisbury, G., et al. (2003), Ground-based PTR-MS measurements of reactive organic compounds during the MINOS campaign in Crete, JulyAugust 2001, Atmos. Chem. Phys., 3, 925-940.

Singh, H. B., and P. R. Zimmerman (1992), Atmospheric distribution and sources of nonmethane hydrocarbons, in Gaseous Pollutants: Characterization and Cycling, edited by J. O. Nriagu, pp. 177-235, Wiley-Interscience, Hoboken, N. J. 
Singh, H., Y. Chen, A. Staudt, D. Jacob, D. Blake, B. Heikes, and J. Snow (2001), Evidence from the Pacific troposphere for large global sources of oxygenated organic compounds, Nature, 410, 1078-1081.

Singh, H. B., A. Tabazadeh, M. J. Evans, B. D. Field, D. J. Jacob, G. Sachse, J. H. Crawford, R. Shetter, and W. H. Brune (2003), Oxygenated volatile organic chemicals in the oceans: Inferences and implications based on atmospheric observations and air-sea exchange models, Geophys. Res. Lett., 30(16), 1862, doi:10.1029/2003GL017933.

Singh, H. B., et al. (2004), Analysis of the atmospheric distribution, sources, and sinks of oxygenated volatile organic chemicals based on measurements over the Pacific during TRACE-P, J. Geophys. Res., 109, D15S07, doi:10.1029/2003JD003883.

Sumner, A. L., et al. (2001), A study of formaldehyde chemistry above a forest canopy, J. Geophys. Res., 106, 24,387-24,405.

Tuazon, E. C., and R. Atkinson (1989), A product study of the gas-phase reaction of methyl vinyl ketone with the $\mathrm{OH}$ radical in the presence of $\mathrm{NO}_{\mathrm{x}}$, Int. J. Chem. Kinet., 21, 1141-1152.

Tuazon, E. C., and R. Atkinson (1990a), A product study of the gas-phase reaction of methylacrolein with the $\mathrm{OH}$ radical in the presence of $\mathrm{NO}_{\mathrm{x}}$, Int. J. Chem. Kinet., 22, 591-602.

Tuazon, E. C., and R. Atkinson (1990b), A product study of the gas-phase reaction of isoprene with the $\mathrm{OH}$ radical in the presence of $\mathrm{NO}_{\mathrm{x}}$, Int. J. Chem. Kinet., 22, 1221-1236.

Usher, C. R., A. E. Michel, and V. H. Grassian (2003), Reactions on mineral dust, Chem. Rev. Washington D.C., 103(12), 4883-4939.

Williams, J. (2004), Organic trace gases in the atmosphere: An overview, Environ. Chem., 1, 125-136, doi:10.1071EN04057.
Williams, J., U. Pöschl, P. J. Crutzen, A. Hansel, R. Holzinger, C. Warneke, W. Lindinger, and J. Lelieveld (2001), An atmospheric chemistry interpretation of mass scans obtained from a proton transfer mass spectrometer flown over the tropical rainforest of Surinam, J. Atmos. Chem., 38 , $133-166$.

Williams, J., R. Holzinger, V. Gros, X. Xu, E. Atlas, and D. W. R. Wallace (2004), Measurements of organic species in air and seawater from the tropical Atlantic, Geophys. Res. Lett., 31, L23S06, doi:10.1029/ 2004GL020012.

Xu, X., J. Williams, C. Plass-Dulmer, H. Berresheim, G. Salisbury, L. Lange, and J. Lelieveld (2003), GC $\times$ GC measurements of $\mathrm{C}_{7}-\mathrm{C}_{11}$ aromatic and n-alkane hydrocarbons on Crete, in air from Eastern Europe during the MINOS campaign, Atmos. Chem. Phys., 3, 1461-1475.

Zhang, Y., and G. R. Carmichael (1999), The role of mineral aerosol in tropospheric chemistry in east Asia: A model study, J. Appl. Meteorol., $38,353-366$

Zhang, Y., Y. Sunwoo, V. Kotamarthi, and G. R. Carmichael (1994), Photochemical oxidant processes in the presence of dust: An evaluation of the impact of dust on particulate nitrate and ozone formation, J. Appl. Meteorol., 33, 813-824.

S. Bartenbach, M. de Reus, H. Fischer, V. Gros, R. Kormann, G. Salisbury, J. Williams, X. Xu, and M. Zöllner, Department of Atmospheric Chemistry, Max-Planck-Institut für Chemie, J.-J.-Becher-Weg 27, D-55128 Mainz, Germany. (williams@mpch-mainz.mpg.de) 